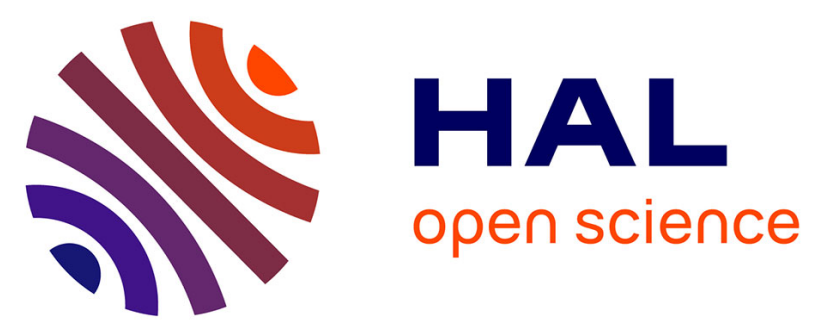

\title{
A heterometallic (Fe6Na8) cage-like silsesquioxane: synthesis, structure, spin glass behavior and high catalytic activity.
}

Alexey N. Bilyachenko, Mikhail M. Levitsky, Alexey I. Yalymov, Alexander A. Korlyukov, Anna V. Vologzhanina, Yuriy N. Kozlov, Lidia S. Shul'Pina, Dmytro S. Nesterov, Armando J. L. Pombeiro, Frédéric Lamaty, et al.

\section{To cite this version:}

Alexey N. Bilyachenko, Mikhail M. Levitsky, Alexey I. Yalymov, Alexander A. Korlyukov, Anna V. Vologzhanina, et al.. A heterometallic (Fe6Na8) cage-like silsesquioxane: synthesis, structure, spin glass behavior and high catalytic activity.. RSC Advances, 2016, 6, pp.48165 - 48180. 10.1039/C6RA07081g . hal-01329780

\section{HAL Id: hal-01329780 https://hal.science/hal-01329780}

Submitted on 1 Feb 2021

HAL is a multi-disciplinary open access archive for the deposit and dissemination of scientific research documents, whether they are published or not. The documents may come from teaching and research institutions in France or abroad, or from public or private research centers.
L'archive ouverte pluridisciplinaire HAL, est destinée au dépôt et à la diffusion de documents scientifiques de niveau recherche, publiés ou non, émanant des établissements d'enseignement et de recherche français ou étrangers, des laboratoires publics ou privés. 


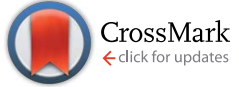

Cite this: RSC Adv., 2016, 6, 48165
Received 17th March 2016

Accepted 5th May 2016

DOI: $10.1039 / \mathrm{c} 6 \mathrm{ra07081g}$

www.rsc.org/advances

\section{A heterometallic $\left(\mathrm{Fe}_{6} \mathrm{Na}_{8}\right)$ cage-like silsesquioxane: synthesis, structure, spin glass behavior and high catalytic activity $\dagger$}

\begin{abstract}
Alexey N. Bilyachenko, ${ }^{\star a b}$ Mikhail M. Levitsky, ${ }^{a}$ Alexey I. Yalymov, ${ }^{a}$ Alexander A. Korlyukov, ${ }^{\text {ac }}$ Anna V. Vologzhanina, ${ }^{a}$ Yuriy N. Kozlov, ${ }^{\text {de }}$ Lidia S. Shul'pina, ${ }^{a}$ Dmytro S. Nesterov, ${ }^{f}$ Armando J. L. Pombeiro, ${ }^{f}$ Frédéric Lamaty, ${ }^{* g}$ Xavier Bantreil, ${ }^{g}$ Amandine Fetre, ${ }^{9}$ Diyang Liu, ${ }^{9}$ Jean Martinez, ${ }^{9}$ Jérôme Long, ${ }^{\text {h }}$ Joulia Larionova, ${ }^{\text {h }}$ Yannick Guari, ${ }^{\text {h }}$ Alexander L. Trigub, ${ }^{i}$ Yan V. Zubavichus, ${ }^{i}$ Igor E. Golub, ${ }^{\text {a }}$ Oleg A. Filippov, ${ }^{a}$ Elena S. Shubina ${ }^{a}$ and Georgiy B. Shul'pin*de

The exotic "Asian Lantern" heterometallic cage silsesquioxane $\left[\left(\mathrm{PhSiO}_{1.5}\right)_{20}\left(\mathrm{FeO}_{1.5}\right)_{6}\left(\mathrm{NaO}_{0.5}\right)_{8}(n\right.$ $\mathrm{BuOH})_{9.6}\left(\mathrm{C}_{7} \mathrm{H}_{8}\right)$ ] (I) was obtained and characterized by X-ray diffraction, EXAFS, topological analyses and DFT calculation. The magnetic property investigations revealed that it shows an unusual spin glass-like behavior induced by a particular triangular arrangement of Fe(III) ions. Cyclohexane and other alkanes as well as benzene can be oxidized to the corresponding alkyl hydroperoxides and phenol, respectively, by hydrogen peroxide in air in the presence of catalytic amounts of complex I and nitric acid. The Icatalyzed reaction of cyclohexane, $c-\mathrm{C}_{6} \mathrm{H}_{12}$, with $\mathrm{H}_{2}{ }^{16} \mathrm{O}_{2}$ in an atmosphere of ${ }^{18} \mathrm{O}_{2}$ gave a mixture of labeled and non-labeled cyclohexyl hydroperoxides, $c-\mathrm{C}_{6} \mathrm{H}_{11}-{ }^{16} \mathrm{O}-{ }^{16} \mathrm{OH}$ and $c-\mathrm{C}_{6} \mathrm{H}_{11}-{ }^{18} \mathrm{O}-{ }^{18} \mathrm{OH}$, respectively, with an ${ }^{18} \mathrm{O}$ incorporation level of ca. $12 \%$. Compound I also revealed high efficiency in the oxidative amidation of alcohols into amides: in the presence of complex l, only 500 ppm of iron was allowed to reach TON and TOF values of 1660 and $92 \mathrm{~h}^{-1}$
\end{abstract}

\section{Introduction}

Iron-oxo compounds attract significant attention from scientific teams worldwide due to their ability to form unique high

${ }^{a}$ Nesmeyanov Institute of Organoelement Compounds, Russian Academy of Sciences, Vavilov Str., 28, 119991 Moscow, Russia. E-mail: bilyachenko@ineos.ac.ru

${ }^{b}$ People's Friendship University of Russia, Miklukho-Maklay Str., 6, 117198 Moscow, Russia

'Pirogov Russian National Research Medical University, Ostrovitianov str., 1, 117997 Moscow, Russia

${ }^{d}$ Semenov Institute of Chemical Physics, Russian Academy of Sciences, ul. Kosygina, dom 4, 119991 Moscow, Russia.E-mail: shulpin@chph.ras.ru

'Plekhanov Russian University of Economics, Stremyannyi pereulok, dom 36, 117997 Moscow, Russia

${ }^{f}$ Centro de Quimica Estrutural, Instituto Superior Técnico, Universidade de Lisboa, Avenida Rovisco Pais, 1049-001 Lisboa, Portugal

${ }^{g}$ Institut des Biomolécules Max Mousseron (IBMM), UMR 5247, CNRS, Université de Montpellier, ENSCM, Site Triolet, Place Eugène Bataillon, 34095 Montpellier cedex 5, France.E-mail: frederic.lamaty@univ-montp2.fr

${ }^{h} I C G M$ - UMR5253 - Equipe IMNO, Université de Montpellier, Place Eugène Bataillon - CC 1502, 34095 Montpellier CEDEX 5, France

${ }^{i}$ National Research Center "Kurchatov Institute”, pl. Akad. Kurchatova, dom 1, 123098 Moscow, Russia

$\dagger$ Electronic supplementary information (ESI) available: CCDC 1452133. For ESI and crystallographic data in CIF or other electronic format see DOI: 10.1039/c6ra07081g clusters (up to 168 iron atoms). ${ }^{1}$ Such complexes are relevant to the field of contemporary molecular magnetism as Single Molecule Magnets (SMMs), ${ }^{2}$ or spin glasses exhibiting slow dynamics of magnetisation. ${ }^{3}$ Additionally, they are widely applied for nanoparticle assembling processes, ${ }^{1 b, 4}$ including several cases of chiral compound aggregation. ${ }^{2 g, 5}$ Also, some data are available concerning gas adsorption of such clusters. ${ }^{6}$ Usually, the design of these architectures is performed by using a self-assembly reaction through the assistance of different types of ligands including oxygen and/or nitrogen based ones, e.g. amino-alcohol or alkoxide containing ligands ${ }^{1 d, 7}$ oximes $^{8}$ or

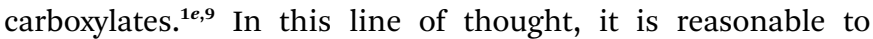
suggest that siloxane ligands, being known for their structural flexibility and readiness to complexation to metal ions, ${ }^{10}$ may be regarded as a versatile tool for the design and synthesis of desired iron-containing compound. Indeed, several examples of such complexes have already been reported. ${ }^{11}$

In this article we present an easy approach to the synthesis of the heteronuclear sodium, iron-oxo cluster in the silsesquioxane $\left(\left[\mathrm{RSiO}_{1,5}\right]_{n}\right)$ framework (compound $\mathbf{I}$ ). A detailed discussion of its structural features is provided. This compound also presents unusual magnetic properties, caused by a particular triangular arrangement of $\mathrm{Fe}(\mathrm{III})$ ions in the crystal structure that induced an appearance of a short range magnetic ordering. A special emphasis is given on the study of the catalytic 
properties of this compound. Note that transition metal complexes, ${ }^{\mathbf{1 2}}$ and in particular, iron-based compounds, ${ }^{\mathbf{1 3}}$ are powerful catalysts in the oxidation of saturated and aromatic hydrocarbons with peroxides. Oxygen-activating proteins and especially enzymes containing polynuclear iron sites attract a great deal of interest. For example, some enzymes with di-iron sites are capable of activating $\mathrm{C}-\mathrm{H}$ bonds. ${ }^{\mathbf{1 4}}$ Methane monooxygenase (MMO) converts alkanes into the corresponding alcohols. The crucial step of the alkane conversion in the active site containing a few bridges can be attributed to hydrogen atom abstraction from an alkane molecule by a radical-like polynuclear iron(IV) and iron(III) species. ${ }^{15}$ It is noteworthy that soluble MMO from M. capsulatus (Bath) oxidizes regioselectively ${ }^{\mathbf{1 6}}$ normal pentane, hexane, and heptane to afford predominately (in the case of $n$-heptane even exclusively) 2 alcohols. ${ }^{17}$ Polynuclear iron complexes containing chelating ligands can serve as models for hydroxylating enzyme centers. $^{18,19}$ Usually polydentate nitrogen-containing ligands have been used in these complexes, and either molecular oxygen or hydrogen peroxide have been employed as oxidant but the efficiency of these systems is rarely high. Compound I containing a polynuclear iron core with chelating oxo-ligands is active in the alkane oxygenation and can be considered as a model of oxidizing enzymes, an "inorganic oxygenase". This work is in direct line with previous reports, since some of us demonstrated that polynuclear copper(II) silsesquioxanes catalyze oxidation of alcohols, benzene ${ }^{20}$ and alkanes ${ }^{21}$ with $\mathrm{H}_{2} \mathrm{O}_{2}$ and tert-BuOOH.

\section{Results and discussion}

\section{Synthesis of compound I}

The simple synthesis of I involves an interaction of sodium siloxanolate $[\mathrm{PhSi}(\mathrm{O}) \mathrm{ONa}]_{n}$ (formed in situ from phenyltriethoxysilane) and anhydrous $\mathrm{FeCl}_{3}$ in the ethanol solution according to Scheme 1 . The reaction was followed by the crystallization of filtrate, which allowed to isolate the single crystals of the cage-like Fe(III), Na-silsesquioxane I (in the yield of 60\%). $\mathrm{X}$-ray diffraction analysis was applied to establish the crystal structure of this compound.

Noteworthy that a classical approach to a metallasilsesquioxanes design through the use of alkoxysilanes implies a stage of silane partial hydrolysis in order to convert the functional SiOR groups into the reactive $\mathrm{Si}-\mathrm{OH}$ fragments. A consequent condensation of the silanol groups leads to the in

$$
\begin{aligned}
\mathrm{PhSi}(\mathrm{OEt})_{3} & \\
1 .+\mathrm{NaOH} & \text { 3. } n-\mathrm{BuOH}, \text { toluene } \\
2 .+\mathrm{FeCl}_{3} & \mathrm{EtOH}_{\mathrm{aq}}
\end{aligned}
$$

Scheme 1 Synthesis of the Fe(III), Na phenylsilsesquioxane I.

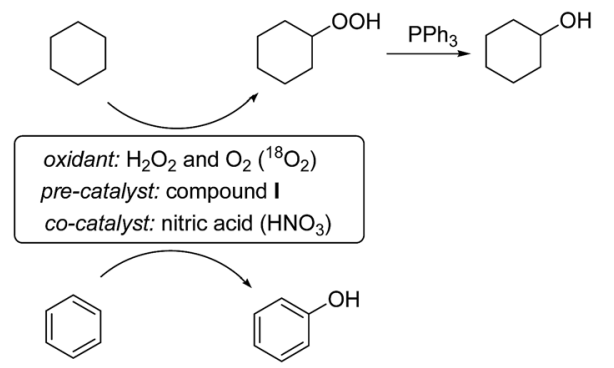

Scheme 2 Oxidation of cyclohexane or benzene catalyzed by complex I.

situ formation of the siloxanolate ligands. Then, these compounds were used for an aggregation of the metallasilsesquioxanes by the interaction with the metal chlorides. ${ }^{22}$ Unfortunately, a condensation of the silanol groups of $\mathrm{RSi}(\mathrm{OH})_{2} \mathrm{ONa}$ incites a formation of a water molecules along with the siloxanolate species, and a risk of the metal chlorides hydrolysis cannot be excluded (Scheme 2). As a result, an assembling of a target metallasilsesquioxane in a high yield is not probable (Fig. 1).

Taking in mind this reasoning, we performed the synthesis of the desired iron containing silsesquioxane compound adding no water to the reaction mixture (Scheme 1). We assumed that amount of water which present in the nonabsolute alcohol would be enough to provide the formation of essential cyclic siloxanolate synthones, with a negligible extent of hydrolysis of $\mathrm{FeCl}_{3}$. We have implemented the interaction of phenyltriethoxysilane with sodium hydroxide in ethanol followed by the addition of dry iron(III) chloride. Finally, just before the filtration, some amount of $n$-butanol and toluene was added to the reaction mixture to precipitate the $\mathrm{NaCl}$ side product. The resulting good yield of the crystallized product ( $\sim 60 \%$ ) confirms the correctness of the suggested approach.

\section{Structure of compound I}

Compound I represents an unusual Asian Lantern-like type of molecular geometry (Fig. 2, left), where silsesquioxane skeleton is formed by the following types of fragments - two cyclic $\left[\mathrm{PhSiO}_{2}\right]_{5}$ and one acyclic $\left[(\mathrm{PhSi})_{10} \mathrm{O}_{21}\right]$ ligands (Fig. 2, right).

These ligands coordinate in the complex way six iron(III) ions or, more exactly, two trinuclear units $\left[\mathrm{Fe}_{3} \mathrm{O}_{12}\right]^{15-}$ (Fig. 3). Structure of latter deserves an additional discussion. Such trinuclear unit is closely related to the widely employed $\mathrm{Fe}_{3}^{\mathrm{III}}\left(\mu_{3}\right.$ O) clusters. For instance, we can cite the family of $\left[\mathrm{Fe}_{3}^{\mathrm{III}}\left(\mu_{3}-\mathrm{O}\right)(\mu-\right.$

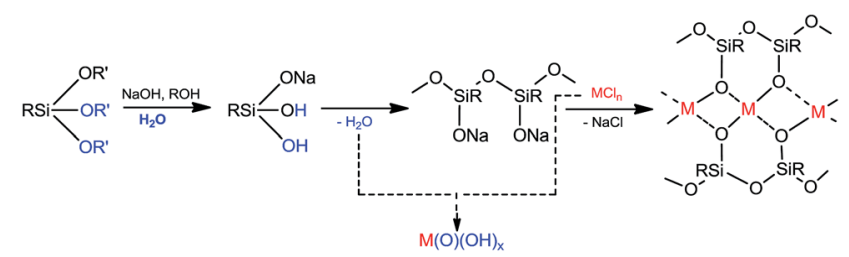

Fig. 1 Simplified mechanism of metallasilsesquioxane formation: purpose reaction and undesirable hydrolysis. 

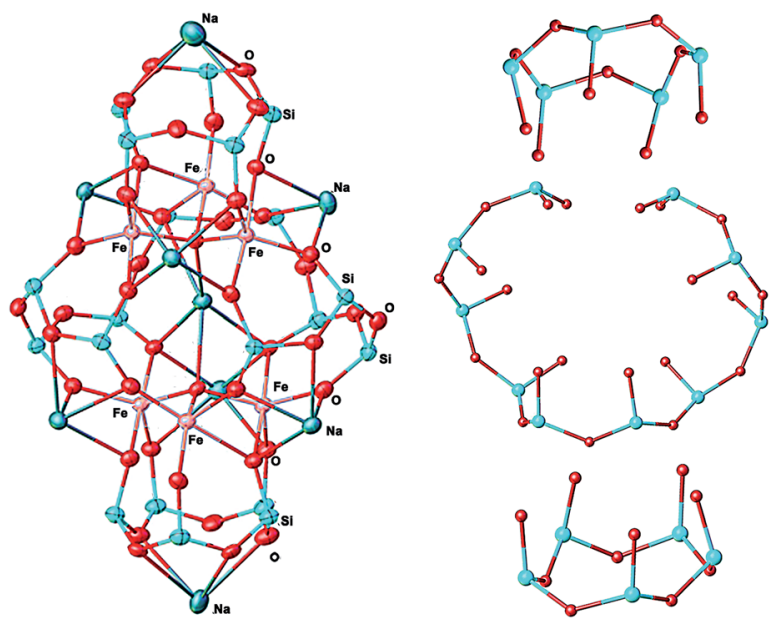

Fig. 2 Structure of I in crystal (left). Structure of silsesquioxane ligands in I (right).

$\left.\left.\mathrm{O}_{2} \mathrm{CR}\right)_{6} \mathrm{~L}_{3}\right]$, where $\mathrm{L}=\mathrm{H}_{2} \mathrm{O}, \mathrm{MeOH}, \mathrm{Py}^{23}$ were used for construction of discrete complexes, $\mathrm{L}=1,5$-dicyanamine was used for the assembly of 1-periodic chains ${ }^{24}$ or $\mathrm{L}=\mathrm{O}_{2} \mathrm{CR}$, $\mathrm{MoO}_{4}{ }^{2-}$ were employed for the synthesis of 2-periodic lattices., ${ }^{9,25}$ One can propose that substitution of bidentatebridge L ligands with a monodentate bridge of polydentate cluster anions should cause distortion of the ( $\mu_{3}$-oxo)-tri-iron(III) cluster. Several structures containing trinuclear iron-oxo units as a part of the structure have already been reported. ${ }^{26}$ Six compounds (including I), matching the search requirements, are listed and discussed in Table S1, ESI. $\dagger$

In turn, sodium ions of compound I are mostly located outside the cage skeleton but one of them, namely $\mathrm{Na} 1$, is encapsulated by inner void of the complex. To our knowledge, this the only known example of cage-like metallasilsesquioxane, encapsulating a positively charged moiety. While instances of neutral (water, pyrazine) and negatively charged $\left(\mathrm{OH}^{-}, \mathrm{Cl}^{-}\right)$ species "capture" are well known in the chemistry of cage metallasiloxanes, ${ }^{27}$ the cage I presents a new style of encapsulation (Fig. S3, ESI $\dagger$ ).

\section{XAS investigations}

Parameters of local surrounding of iron atoms in I retrieved from Fe K-edge EXAFS are fully consistent with X-ray (Fig. 4). First shell of oxygen atoms for nonequivalent iron atoms were

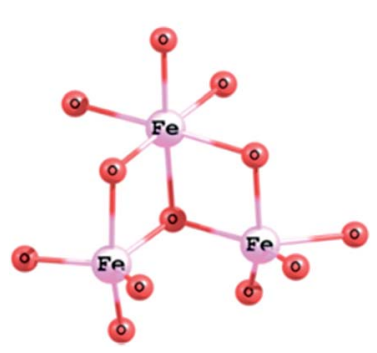

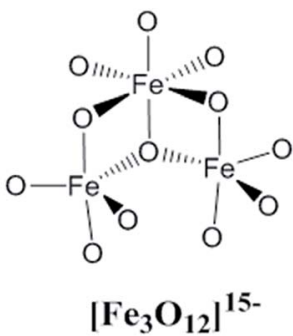

Fig. 3 The triangular iron-oxo fragment similar for the six structures.

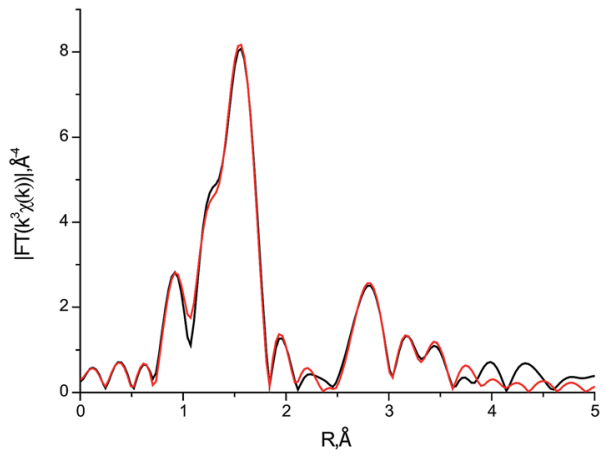

Fig. 4 Fourier transform of Fe K-edge EXAFS spectrum for I: experiment (black line) and best fit (red line).

fitted by the three distances $1.94 \AA$ (1.89-1.93 $\mathrm{A}), 2.09 \AA$ (1.98$2.04 \AA$ ) and $2.26 \AA$ (2.14-2.19 $\mathrm{\AA})$. Values in parentheses correspond to distance ranges from X-ray. The comparison of the radii for other atomic shells is presented in Table S2, ESI. $\dagger$

The XANES spectra (Fig. 5) were used to investigate the symmetry of the metal sites and the oxidation state of metal ion, which is of crucial significance for discussion of the magnetic properties of the compound (see below). Energy scale was calibrated using Fe foil which spectrum was measured simultaneously with the sample. According to a XANES study of a row of minerals containing iron made by Wilke et al. ${ }^{28}$ a pre-edge peak of Fe K-edge XANES spectra can be used to investigate oxidation state of iron atoms. For $\mathrm{Fe}^{3+}$ samples the energy position of this peak is in the range between 7113 and $7116 \mathrm{eV}$. The pre-edge peak position $(\sim 7115 \mathrm{eV})$ for sample I points that iron atom is in the $\mathrm{Fe}^{3+}$ oxidation state.

\section{Magnetic properties}

The magnetic properties of I were investigated using a SQUID magnetometer working in the temperature range $1.8-350 \mathrm{~K}$ up to $7 \mathrm{~T}$ (Fig. 6). The room temperature value of $\chi T$ is equal to $30.70 \mathrm{~cm}^{3} \mathrm{~K} \mathrm{~mol}^{-1}$. This value is higher than the theoretical value of $26.25 \mathrm{~cm}^{3} \mathrm{~K} \mathrm{~mol}^{-1}$ expected for six non-interacting Fe(III) ions $(S=5 / 2$ and $g=2.00)$. This discrepancy most likely originates from the occurrence of ferromagnetic

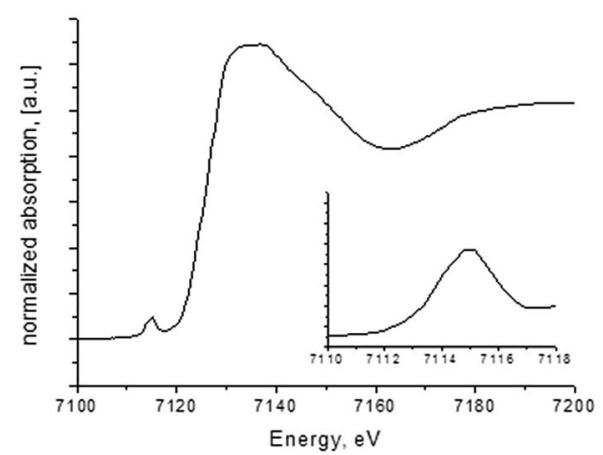

Fig. 5 Experimental Fe K-edge XANES spectra for sample I. Pre-edge region is shown in the inset. 


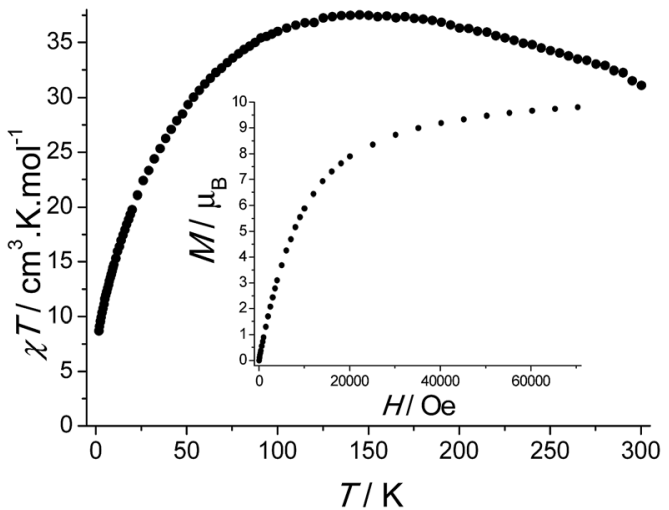

Fig. 6 Temperature dependence of $\chi^{T}$ under a 1000 Oe DC field performed for sample I. Inset: field dependence of the magnetisation at $1.8 \mathrm{~K}$.

interactions between the spin carriers that are still operative at room temperature. This scenario is confirmed by the temperature dependence of the $\chi T$ product, which reveals an increase up to a maximum for a temperature of $145 \mathrm{~K}$ before decreasing to reach the value of $8.72 \mathrm{~cm}^{3} \mathrm{~K} \mathrm{~mol}^{-1}$ at $1.8 \mathrm{~K}$. Consequently, the increase of $\chi T$ can be ascribed to the presence of ferromagnetic interactions between three Fe(III) ions of a triangle unit shown in Fig. 7, while the decrease may be inputted to antiferromagnetic interactions between the two triangles constituting the cluster (see Fig. 2) and/or the occurrence of zero-field splitting. The field dependence of the magnetization performed at $1.8 \mathrm{~K}$ yields to a value of $9.81 \mu_{\mathrm{B}}$ at $7 \mathrm{~T}$ without evidence of a saturation indicating the presence of a magnetic anisotropy.

At $1.8 \mathrm{~K}$, a clear opening of the hysteresis loop can be observed with a small coercive field of 40 Oe (Fig. S4, ESI $\dagger$ ) suggesting the presence of a blocking of the magnetization at low temperature. In order to study in detail the origin of this phenomenon, alternative currents (AC) measurements were performed. The temperature dependence of the AC susceptibility, its in-phase $\left(\chi^{\prime}\right)$ and out-of-phase $\left(\chi^{\prime \prime}\right)$ components, measured in zero DC magnetic field in the 1 to $1500 \mathrm{~Hz}$ frequency range shows a series of frequency dependent peaks (Fig. 8). At $1 \mathrm{~Hz}$, the maximum of $\chi^{\prime \prime}$ is observed at $6.4 \mathrm{~K}$; it progressively shifts to higher temperatures as the frequency

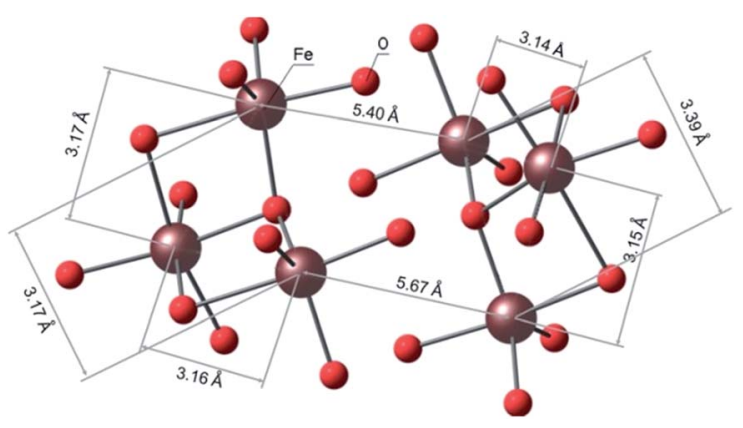

Fig. 7 Representation of triangular Fe units for I.

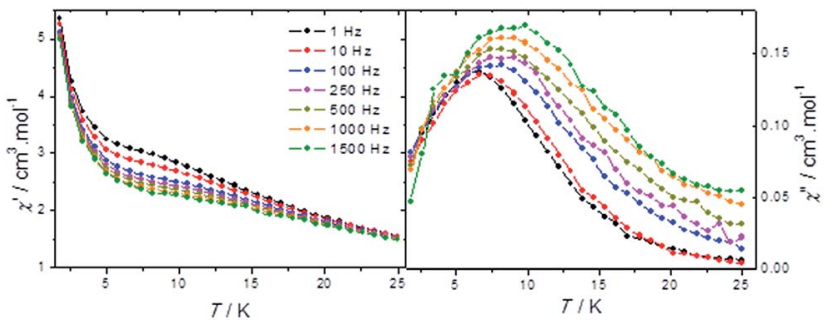

Fig. 8 Temperature dependence of the in-phase $\left(\chi^{\prime}\right)$ and out-ofphase $\left(\chi^{\prime \prime}\right)$ susceptibilities.

increases with an increase in its intensity. Correspondingly, the maximum of the $\chi^{\prime}$ peak shifts to higher temperature with frequency, but the peak's intensity decreases. Such behavior is frequently interpreted as a signature of a short range magnetic ordering arising from the slow dynamic of the magnetization.

In general, the slow dynamic of individual clusters is usually assigned to the presence of a single large magnetic moment. In this respect, three magnetic behaviors may be identified, based on the type and the magnitude of inter- or intra-cluster interactions. Firstly, magnetically non-interacting molecules may be described as non-interacting magnetic moments that give rise to an appearance of the superparamagnetism. ${ }^{29}$ In this case, the relaxation time, $\tau$, obeys an Arrhenius law, $\tau=\tau_{0} \exp \left(U_{\text {eff }} / k_{\mathrm{B}} T\right)$ (where $U_{\text {eff }}$ is the average energy barrier for the reversal of the magnetization, $\tau_{0}$ is the attempt time and $k_{\mathrm{B}}$ is the Boltzmann constant) and becomes equal to the measuring time $\tau_{\mathrm{m}}$. For sample I, the Arrhenius law fitting of the blocking temperature obtained from the $\chi^{\prime \prime}$ maxima for different observation times $\tau$ $=1 / 2 \pi \nu$ (with $\nu$ being the frequency of the oscillating field) gives the $U_{\text {eff }}$ and the $\tau_{0}$ values equal to $164.49 \mathrm{~K}$ and $7.55 \times 10^{-13} \mathrm{~s}$, respectively. The obtained $\tau_{0}$ value is slightly lower than those expected for pure superparamagnetic systems $\left(10^{-8}\right.$ to $10^{-12}$ s). ${ }^{30}$ This is confirmed by the Mydosh parameter value of $\varphi=$ $0.090\left(\varphi=\left(T_{\max }-T_{\min }\right) /\left(T_{\max } \times \log \nu_{\max }-\log \nu_{\min }\right)\right)$ which indicates the amplitude of the out-of-phase peaks' shift with frequency. This value is slightly lower than the value observed for classical superparamagnets $(>0.1)$.

Secondly, the short range magnetic ordering may also be induced by a spin-glass like behavior, caused by the presence of strong dipolar interactions between the magnetic clusters. ${ }^{31}$ However, since the later are largely separated in the crystal by
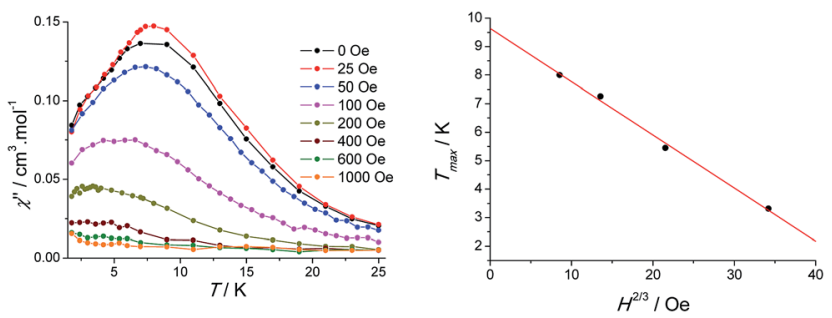

Fig. 9 Left: Temperature dependence of out-of-phase susceptibilities $\left(\chi^{\prime \prime}\right)$ for various DC magnetic fields. Right: Field dependence of the temperature maximum of $\chi^{\prime \prime}$ as a function of field (Almeida-Thouless line). 
bulky ligands (the shortest distance between iron ions in neighboring cages is $14.54 \AA$ ), this phenomenon may be not dominant and then ruled out.

Thirdly, the observed dynamic behavior may be attributed to the intrinsic spin-glass behavior relative to a single cluster, which may be caused by intrinsic volume or surface spin frustration. In order to confirm this, the temperature dependence of the AC susceptibilities (at the frequency of $100 \mathrm{~Hz}$ ) was measured as a function of an applied DC magnetic field (Fig. 9, left). Upon increasing DC field, the peaks of $\chi^{\prime \prime}$ component shift to lower temperatures and completely vanished for the fields larger than 600 Oe, highlighting a disappearance of a shortrange magnetic ordering. The temperature maximum of $\chi^{\prime \prime}$ decreases linearly with $H^{2 / 3}$ which corresponds to the AlmeidaThouless line, confirming an evidence of a spin glass-like behaviour. ${ }^{32}$ An extrapolation at $H=0$ Oe gives the freezing temperature at $9.6 \mathrm{~K}$ (Fig. 9, right).

Such spin-glass behavior may be explained by a particular arrangement of six $\mathrm{Fe}(\mathrm{III})$ ions in the crystal structure of $\mathbf{I}$. Indeed, they are situated in the corner of two crystallographically independent equilateral triangles (Fig. 7) with the shortest iron-iron distance ranging from 3.138 to 3.392 A. The triangular topology is usually considered as an archetype of the geometrically frustrated spins, which may induce an appearance of a spin glass-like behavior of isolated molecules as we previously observed in triangular Co-based metallasilsesquioxane system. ${ }^{10 h}$ Note that this phenomenon has also been observed in small nanoparticles with surface or volume spin frustration, ${ }^{33}$ or for geometrically frustrated garnet-type structures. ${ }^{34}$

\section{Theoretical (DFT) calculations}

Full geometry optimization of $\mathrm{Na}_{8} \mathrm{Fe}_{6} \mathrm{Si}_{20} \mathrm{C}_{120} \mathrm{H}_{100} \mathrm{O}_{43}$ (X-ray structure of I with removed solvent shell, I_QM) was provided with Gaussian09 (ref. 35) program package using the two-layer ONIOM $^{36}$ approach. High layer includes $\mathrm{Si}-\mathrm{O}-\mathrm{Fe}$ framework with $\mathrm{Na}$ atoms, and was described by unrestricted open shell approach (M06 (ref. 37) functional with spin-state-corrected s6$31 \mathrm{G}(\mathrm{d})^{38}$ basis set for Fe atom and 6-31G(d,p) for other atoms). $\mathrm{Ph}$ groups attached to Si atoms were in low layer described with semi-empirical PM6 (ref. 39) method. Optimized structure of I_QM slightly differs from crystal structure.

The optimized geometry reproduced quite well the siloxane core (the difference between the calculated and experimentally observed for $\mathrm{Fe}-\mathrm{O}(\mathrm{Fe})$ bonds and $\mathrm{Si}-\mathrm{O}(\mathrm{Si})$ are less than $0.06 \AA$ ) while other bonds is slightly overestimated $r[\mathrm{Fe}-\mathrm{O}(\mathrm{Si})]$ and $r[\mathrm{Si}-$ $\mathrm{O}(\mathrm{Fe})]$ but not more than $0.13 \AA$. The quantum chemical calculation reveals six non-interacting Fe atoms with Muliken atomic spin density in range 1.2-1.5 when total multiplicity of molecule was 11 (Table 1).

\section{Catalytic oxidation of hydrocarbons with $\mathrm{H}_{2} \mathrm{O}_{2}$}

We have found that cyclohexane and other alkanes as well as benzene can be oxidized in acetonitrile solution to the corresponding alkyl hydroperoxides and phenol, respectively, by hydrogen peroxide in air in the presence of catalytic amounts of complex I and nitric acid, as shown in Scheme 2. The reaction
Table 1 Geometry parameters (distances, Å) of crystal structure and optimized ONIOM-model of I

\begin{tabular}{lll}
\hline & Crystal of I & ONIOM-model of I \\
\hline $\mathrm{Si}-\mu^{2}-\mathrm{O}(\mathrm{Si})$ & $1.614-1.666$ & $1.592-1.709$ \\
$\mathrm{Si}-\mu^{2}-\mathrm{O}(\mathrm{Fe})$ & $1.582-1.610$ & $1.563-1.701$ \\
$\mathrm{Fe}-\mu^{2}-\mathrm{O}(\mathrm{Si})$ & $1.893-1.995$ & $1.770-2.061$ \\
$\mathrm{Fe}-\mu^{3}-\mathrm{O}(\mathrm{Si})(\mathrm{Fe})$ & $2.040-2.377$ & $1.920-2.246$ \\
$\mathrm{Fe}-\mu^{3}-\mathrm{O}(\mathrm{Fe})_{2}$ & $1.910-2.024$ & $1.849-2.011$ \\
\hline
\end{tabular}

proceeds in acetonitrile solution under mild conditions (typically at $50{ }^{\circ} \mathrm{C}$ ). The alkyl hydroperoxide is relatively stable in the solution, and can be easily reduced by $\mathrm{PPh}_{3}$ to the corresponding alcohol.

We studied kinetics of the cyclohexane oxidation. Products of the hydrocarbon oxidation were quantified by GC. If the direct injection of a reaction sample (of the alkane oxidation with $\mathrm{O}_{2}$ or/and $\mathrm{H}_{2} \mathrm{O}_{2}$ ) into the chromatograph gave comparable amounts of cyclohexanol and cyclohexanone, the reduction of the sample with $\mathrm{PPh}_{3}$ prior to GC analysis (for this method developed earlier by one of us, see ref. 40) led to the noticeable predominance of the alcohol. This comparison clearly indicates that cyclohexyl hydroperoxide was formed as the main primary product. The formation of cyclohexyl hydroperoxide and its
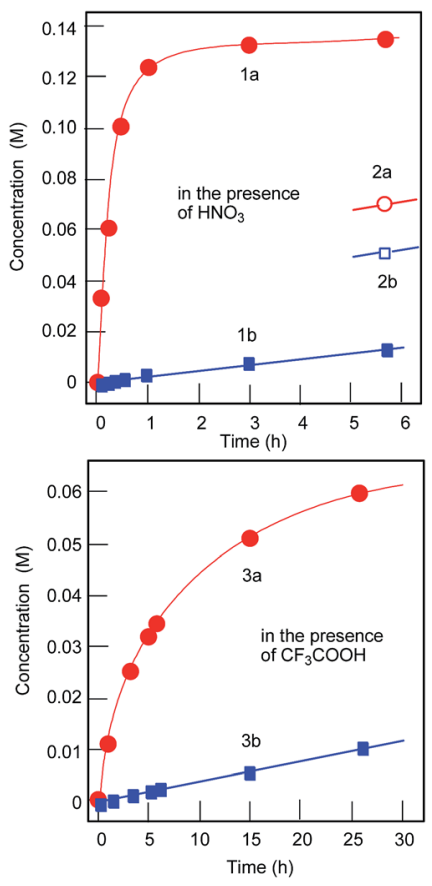

Fig. 10 Accumulation of cyclohexanol (curves a) and cyclohexanone (curve b) in the cyclohexane oxidation with hydrogen peroxide catalyzed by I $\left(2 \times 10^{-4} \mathrm{M}\right)$ in the presence of acids $(0.05 \mathrm{M})$ : $\mathrm{HNO}_{3}$ (curves 1 and 2) and $\mathrm{CF}_{3} \mathrm{COOH}$ (curves 3). Solvent was acetonitrile (total volume of the reaction solution was $5 \mathrm{~mL}$ ); $30{ }^{\circ} \mathrm{C}$. Other conditions: cyclohexane, $0.46 \mathrm{M} ; \mathrm{H}_{2} \mathrm{O}_{2}$ (50\% aqueous), $1.5 \mathrm{M}$. Amounts of cyclohexanone and cyclohexanol were determined after reduction of the aliquots with solid $\mathrm{PPh}_{3}$. Curves 2 are the same as curves 1 but the concentrations have been determined without reduction of the aliquots with solid $\mathrm{PPh}_{3}$ (for this method, see ref. 40). 

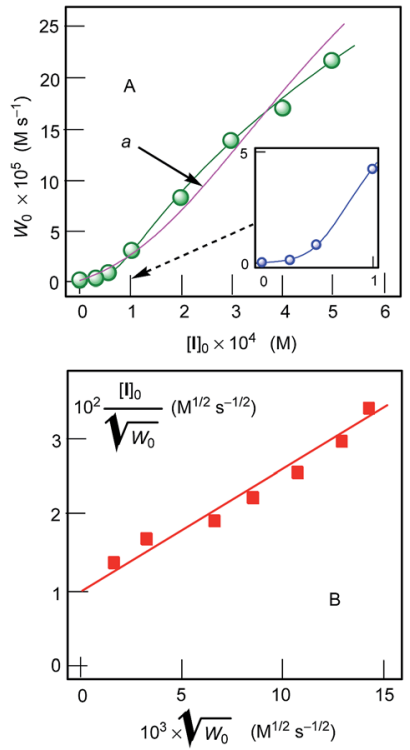

Fig. 11 Graph A: Dependence of the initial rate of oxygenate (a sum cyclohexanol + cyclohexanone) formation $W_{0}$ on initial concentration of $\mathrm{I}$ in the oxidation of cyclohexane $(0.46 \mathrm{M})$ with hydrogen peroxide (50\% aqueous) catalyzed by compound $\mathrm{I}$ in the presence of $\mathrm{HNO}_{3}$ $(0.05 \mathrm{M})$ in $\mathrm{MeCN}$ at $30^{\circ} \mathrm{C}$. Concentrations of cyclohexanone and cyclohexanol were determined after reduction of the aliquots with solid PPh ${ }_{3}$. Pink curve "a" is a calculated curve (see the text). Graph B: linearization of the curve presented in Graph A. For kinetic analysis of this dependence, see ESI. $\dagger$

reduction to cyclohexanol with $\mathrm{PPh}_{3}$ is depicted in Scheme 2 . This method gives very valuable information on the existence or non-existence of alkyl peroxides in the reaction mixture and allows us to estimate concentrations of the three products (ketone, alcohol and alkyl hydroperoxide) formed in the reaction. In our kinetic studies, for precise determination of oxygenate concentrations, data exclusively obtained after reduction of the sample with $\mathrm{PPh}_{3}$ were usually used. We will

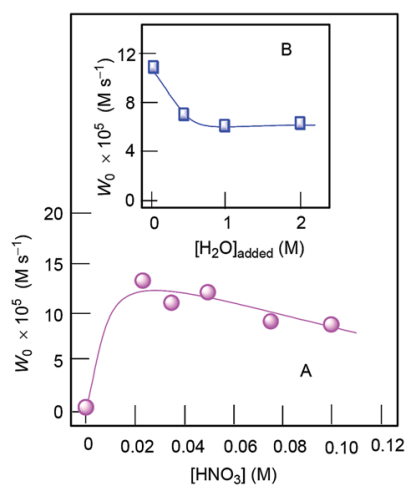

Fig. 12 Dependences of the initial rate of oxygenate formation $W_{0}$ on concentration of added $\mathrm{HNO}_{3}$ (Graph A) and $\mathrm{H}_{2} \mathrm{O}$ (Graph B) in the oxidation of cyclohexane $(0.46 \mathrm{M})$ with hydrogen peroxide $(50 \%$ aqueous; $1.5 \mathrm{M})$ catalyzed by compound I $\left(2 \times 10^{-4} \mathrm{M}\right)$ and $\mathrm{HNO}_{3}$ $(0.05 \mathrm{M})$ in $\mathrm{MeCN}$ at $30{ }^{\circ} \mathrm{C}$. Concentrations of cyclohexanone and cyclohexanol were determined after reduction of the aliquots with solid $\mathrm{PPh}_{3}$. operate in this paper with the initial rate of the formation of a sum of cyclohexyl hydroperoxide, cyclohexanol and cyclohexanone which is determined as the sum of cyclohexanol and cyclohexanone after reduction with $\mathrm{PPh}_{3}$. This rate $W_{0}=(\mathrm{d}$ [products] $/ \mathrm{d} t)_{0}$ is equal to the initial rate of the formation of oxygenates.

\section{Selectivity parameters for the catalytic oxidation of hydrocarbons}

To get an insight into the nature of oxidizing species, we measured the selectivity parameters in oxidations of certain linear, branched and cyclic saturated hydrocarbons. The regioselectivity parameter determined for the oxidation, by the system under consideration, of $n$-heptane is relatively low, i.e. $\mathrm{C}(1): \mathrm{C}(2): \mathrm{C}(3): \mathrm{C}(4) \approx 1: 7.1: 7.0: 6.5$. These values are close to the parameters determined previously for systems which oxidize alkanes with the participation of hydroxyl radicals. ${ }^{41}$ As in the case of linear alkanes, the bond-selectivity parameter $\left(1^{0}: 2^{0}: 3^{0}\right)$ in the oxidation of methylcyclohexane catalyzed by $\mathbf{I}(1: 7.1: 22.2$; see Fig. S5 $\dagger)$ is close to the corresponding values found for the systems oxidizing alkanes with hydroxyl radicals. ${ }^{41 b, 41 c}$ The oxidation of cis- and trans-1,2dimethylcyclohexanes proceeds non-stereoselectively because the trans/cis ratios of isomeric alcohols (after reduction with $\mathrm{PPh}_{3}$ ) were close to unity, namely 0.9. Thus, on the basis of the selectivity parameters, we can assume that the alkane oxidation reactions catalyzed by compound I proceed via the formation of hydroxyl radicals.

\section{Kinetics of the catalytic hydrocarbon oxygenation}

Stirring a solution of cyclohexane, $\mathrm{CyH}$, in acetonitrile at $30^{\circ} \mathrm{C}$ with $50 \%$ aqueous hydrogen peroxide in the presence of compound $\mathbf{I}$ and nitric acid leads to oxygenation of the alkane (Fig. 10, curves 1). The reaction is noteciably slower in the

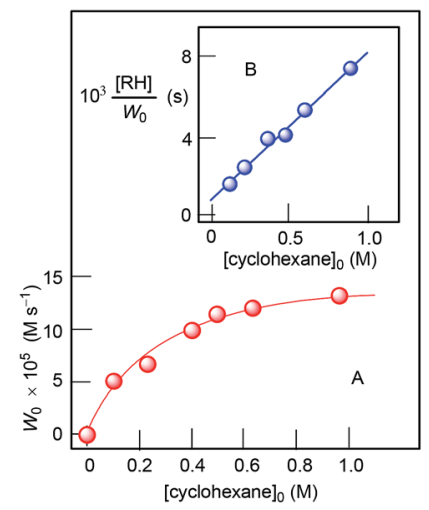

Fig. 13 Dependences of oxidation rate $W_{0}$ on initial concentration of cyclohexane (Graph A) in the oxidation of cyclohexane with $\mathrm{H}_{2} \mathrm{O}_{2}(50 \%$ aqueous). Conditions: $\left[\mathrm{I}_{0}=2 \times 10^{-4} \mathrm{M},\left[\mathrm{HNO}_{3}\right]_{0}=0.05 \mathrm{M}\right.$, solvent $\mathrm{MeCN}, 30{ }^{\circ} \mathrm{C}$. Concentrations of the products (cyclohexanol and cyclohexanone) were measured after reduction with $\mathrm{PPh}_{3}$. Graph B: Linearization of dependence presented by Graph A using coordinates $[\text { cyclohexane }]_{0}-[\mathrm{RH}]_{0} / W_{0}$. For kinetic analysis of this dependence, see ESI. $\dagger$ 


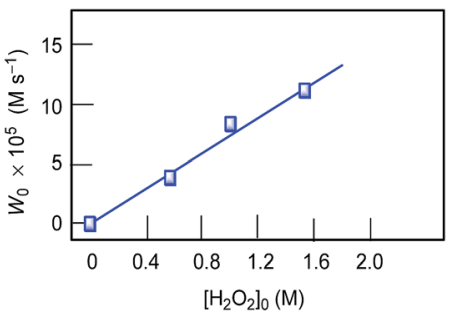

Fig. 14 Dependences of oxidation rate $W_{0}$ on initial concentration of hydrogen peroxide in the oxidation of cyclohexane $(0.46 \mathrm{M})$ with $\mathrm{H}_{2} \mathrm{O}_{2}$ (50\% aqueous). Conditions: $\left[\mathrm{I}_{0}=2 \times 10^{-4} \mathrm{M},\left[\mathrm{HNO}_{3}\right]_{0}=0.05 \mathrm{M}\right.$, solvent $\mathrm{MeCN}, 30^{\circ} \mathrm{C}$. Concentrations of the products (cyclohexanol and cyclohexanone) were measured after reduction with $\mathrm{PPh}_{3}$.

absence of an acid promoter. Trifluoroacetic acid also accelerates the oxidation, although less efficiently (Fig. 10, curves 2).

We studied the dependence of the initial rate $W_{0}$ of cyclohexane oxidation on the concentration of catalyst I (Fig. 11). It can be clearly seen that the dependence curve has an S-shape.

Dependences of initial oxidation rate on the concentration of co-catalyst $\mathrm{HNO}_{3}$ as well as of added water are presented in Fig. 12. The role of added nitric or trifluoroacetic acid is not completely clear. We can assume that protons from these acids promotes splitting certain bonds in the precatalyst I. This leads to facilitation of approaching oxidant and substrate to the metal reaction centres. We realize that the full structure of precatalyst I can be more or less substantially modified under the action of the acid as well in the presence of $\mathrm{H}_{2} \mathrm{O}_{2}$.
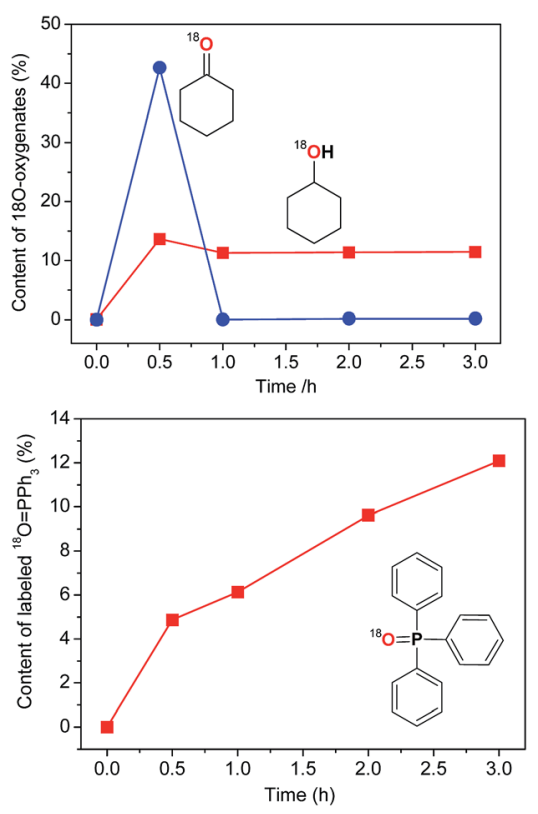

Fig. 15 Incorporation of the labelled oxygen into cyclohexanol and cyclohexanone (top) and triphenylphosphine oxide (bottom) in the course of the cyclohexane oxidations with subsequent reduction of the reaction sample with $\mathrm{PPh}_{3}$. Conditions: $\left[\mathrm{I}_{0}=2 \times 10^{-4} \mathrm{M}\right.$; $\left[\mathrm{HNO}_{3}\right]_{0}$ $=0.05 \mathrm{M} ;\left[\mathrm{H}_{2} \mathrm{O}_{2}\right]_{0}=1.5 \mathrm{M}$; [cyclohexane $]_{0}=0.46 \mathrm{M} ; 30{ }^{\circ} \mathrm{C} ;{ }^{18} \mathrm{O}_{2} 1 \mathrm{bar}$. The yields and isotopic abundances were measured after reduction of the reaction samples with $\mathrm{PPh}_{3}$.
The curve of dependence of $W_{0}$ on the initial concentration of cyclohexane is approaching a plateau at $[\mathrm{CyH}]_{0}>0.4 \mathrm{M}$ (Fig. 13, Graph A). The rate dependence on initial concentration of hydrogen peroxide is linear at $\left[\mathrm{H}_{2} \mathrm{O}_{2}\right]_{0}<1.6 \mathrm{M}$ (Fig. 14). For kinetic analysis of all dependences, see ESI. $\dagger$

\section{Experiments on the alkane oxidation in the presence of ${ }^{18} \mathrm{O}_{2}$ and $\mathrm{H}_{2}{ }^{18} \mathrm{O}$}

The experiments with isotopically labeled species are useful mechanistic probes to determine the reaction mechanisms. It was shown previously that cycloalkane oxidation, catalysed by non-heme iron species, in an ${ }^{18} \mathrm{O}_{2}$ atmosphere results in a wide range of incorporation percentages, depending on the reaction mechanism. ${ }^{11 a}$ Based on the results taken from the literature and on our recent studies on incorporation of labeled oxygen $^{21,41 a, b, c}$ in the cyclohexane oxidation, we performed a similar study for the catalyst $\mathbf{I}$.

The accumulation of labeled oxygenated products with time was studied for conditions $[\mathbf{I}]_{0}=2 \times 10^{-4} \mathrm{M}$ and $30^{\circ} \mathrm{C}$ under the atmosphere of ${ }^{18} \mathrm{O}_{2}$ (if all ${ }^{18} \mathrm{O}_{2}$ is conventionally considered as dissolved in the reaction mixture its concentration is $0.21 \mathrm{M}$ ). The yields and isotopic abundances were measured after reduction of the reaction samples with $\mathrm{PPh}_{3}$. The highest degree $(14 \%)$ of ${ }^{18} \mathrm{O}$ incorporation into the cyclohexanol formed from $\mathrm{CyOOH}$ and $\mathrm{PPh}_{3}$ was observed at the beginning of the reaction (Fig. 15, top graph), then reaching a plateau at $11 \%$ level.

This degree is considerably lower than those observed previously for complexes of osmium $(68 \%)^{41 c}$ and copper
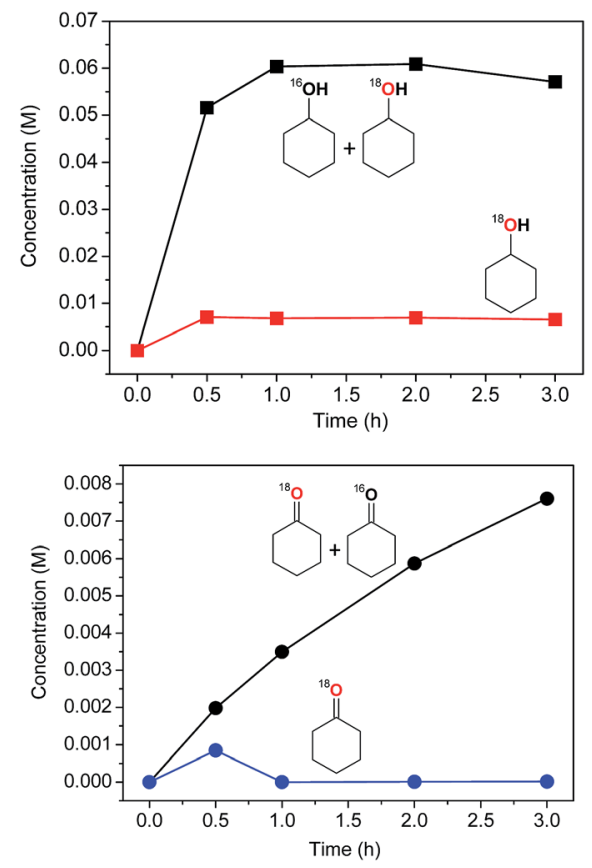

Fig. 16 Kinetic curves of accumulation with time of cyclohexanol (top) and cyclohexanone (bottom) containing both partially labeled (the sum ${ }^{16} \mathrm{O}+{ }^{18} \mathrm{O}$ ) and completely ${ }^{18} \mathrm{O}$-labeled oxygenates. For conditions of the experiments, see caption to Fig. 15. The yields and isotopic abundances were measured after reduction of the reaction samples with $\mathrm{PPh}_{3}$. 

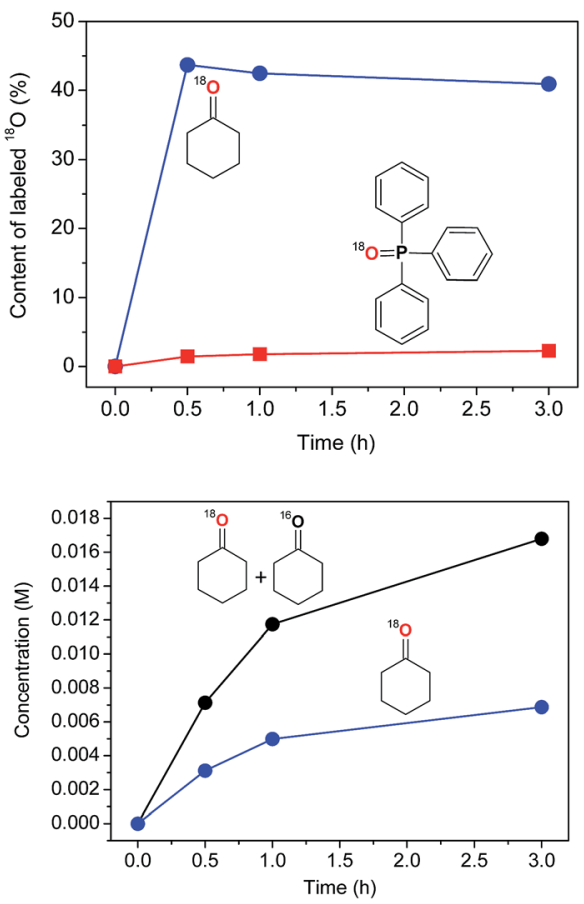

Fig. 17 Incorporation of labeled oxygen into cyclohexanone and triphenylphosphine oxide (top) in the course of the cyclohexane oxidations. Conditions: $[\mathrm{I}]_{0}=2 \times 10^{-4} \mathrm{M}$; $\left[\mathrm{HNO}_{3}\right]_{0}=0.05 \mathrm{M} ;\left[\mathrm{H}_{2} \mathrm{O}_{2}\right]_{0}$ $=0.91 \mathrm{M}$; [cyclohexane $]_{0}=0.48 \mathrm{M} ; 30{ }^{\circ} \mathrm{C}_{;}\left[\mathrm{H}_{2}{ }^{18} \mathrm{O}\right]_{0}=2.15 \mathrm{M}$. Kinetic curves of accumulation with time of cyclohexanone containing both partially labeled (the sum ${ }^{16} \mathrm{O}+{ }^{18} \mathrm{O}$ ) and completely ${ }^{18} \mathrm{O}$-labeled oxygenates are shown in the bottom graph. The yields and isotopic abundances were measured after reduction of the reaction samples with $\mathrm{PPh}_{3}$.

$(50 \%)^{21}$ under similar reaction conditions. Lower incorporation of ${ }^{18} \mathrm{O}$ can be due to relatively low activity of $\mathbf{I}$ at the studied conditions with the overall yield of products based on the cyclohexane of $c a .14 \%$.

The origin of the non-labelled $\left({ }^{16} \mathrm{O}\right)$ portion of cyclohexanol is the ${ }^{16} \mathrm{O}$-water, present in the reaction mixture, and ${ }^{16} \mathrm{O}-$ hydrogen peroxide. One may expect the incorporation of the ${ }^{18} \mathrm{O}$ isotope into the formed triphenylphosphine oxide $\left(\mathrm{O}=\mathrm{PPh}_{3}\right)$ via the following reaction scheme where the alkyl hydroperoxide is reduced to alcohol by phosphine:

$$
\mathrm{Cy}-{ }^{18} \mathrm{O}^{18} \mathrm{OH}+\mathrm{PPh}_{3} \rightarrow \mathrm{Cy}-{ }^{18} \mathrm{OH}+{ }^{18} \mathrm{O}=\mathrm{PPh}_{3}
$$

Simultaneously the reduction of remaining non-labeled hydrogen peroxide gives ${ }^{16} \mathrm{O}=\mathrm{PPh}_{3}$ :

$$
\mathrm{H}^{16} \mathrm{O}^{16} \mathrm{OH}+\mathrm{PPh}_{3} \rightarrow \mathrm{H}^{16} \mathrm{OH}+{ }^{16} \mathrm{O}=\mathrm{PPh}_{3}
$$

The catalytic system based on I demonstrates a gradual accumulation of ${ }^{18} \mathrm{O}=\mathrm{PPh}_{3}$ reaching a $12 \%$ incorporation level after $3 \mathrm{~h}$ reaction time (Fig. 16, bottom graph).

The mode of dependence of the ${ }^{18} \mathrm{O}$ incorporation into the cyclohexanone is different from that obtained for cyclohexanol
(Fig. 15 and 16). Although the maximum percentage of labeled ketone exceeds $40 \%$ (Fig. 17), the absolute concentration of this compound is quite low and, moreover, falls to nearly zero levels at $1 \mathrm{~h}$ reaction time. This effect can be explained by a rapid oxygen exchange of ${ }^{18} \mathrm{O}$-labeled ketone with excess of ${ }^{16} \mathrm{O}$-water present in the reaction mixture. It is necessary to mention that recently Talsi, Bryliakov and coworkers ${ }^{\mathbf{4 1 d , 4 1 e}}$ demonstrated that the blank process which proceeds in acidic medium $\left(\left[c-\mathrm{C}_{6} \mathrm{H}_{10}=\right.\right.$ $\mathrm{O}]_{0}=0.25 \mathrm{M},\left[\mathrm{HNO}_{3}\right]=0.05 \mathrm{M},\left[\mathrm{H}_{2}{ }^{18} \mathrm{O}\right]=2.37 \mathrm{M}$ and $\left[\mathrm{H}_{2}{ }^{16} \mathrm{O}\right]=$ $0.08 \mathrm{M}$ ) in $\mathrm{CH}_{3} \mathrm{CN}$ gives $82 \%$ of ${ }^{18} \mathrm{O}$ incorporation into $c-\mathrm{C}_{6} \mathrm{H}_{10}=$ $\mathrm{O}$ measured after 10 and $20 \mathrm{~min}$ time. Unfortunately, this side process does not allow us to estimate correctly the amount of cyclohexanone $-{ }^{18} \mathrm{O}$ formed in the catalytic oxidation of cyclohexane.

In contrast to the reaction under ${ }^{18} \mathrm{O}_{2}$, no incorporation of labeled oxygen into cyclohexanol was observed when the reaction with the $\mathrm{H}_{2}{ }^{16} \mathrm{O}_{2} /{ }^{16} \mathrm{O}_{2}$ combination is carried out in the presence of $2.15 \mathrm{M}$ of $\mathrm{H}_{2}{ }^{18} \mathrm{O}$. Cyclohexanone was found to exhibit the highest level of ${ }^{18} \mathrm{O}$ content of $44 \%$ which is constant in time (Fig. 17). This indicates that labeled ketone $c$ $\mathrm{C}_{6} \mathrm{H}_{10}={ }^{18} \mathrm{O}$ comes most probably from the exchange reaction between cyclohexanone and $\mathrm{H}_{2}{ }^{18} \mathrm{O}$ (at the $\left[\mathrm{H}_{2}{ }^{18} \mathrm{O}\right]_{0} /[\mathrm{CyH}]_{0}=4.5$ ratio). Triphenylphosphine oxide $\left(\mathrm{O}=\mathrm{PPh}_{3}\right)$ was found to contain $c a .2 .5 \%$ of ${ }^{18} \mathrm{O}$. Assuming that the only way for oxygen to appear in the $\mathrm{O}=\mathrm{PPh}_{3}$ is the oxidation of $\mathrm{PPh}_{3}$ with the oxygen-containing peroxo species, such as cyclohexyl hydroperoxide $\mathrm{Cy}-\mathrm{OOH}$, one may suppose that a small portion of $\mathrm{Cy}-$ $\mathrm{OOH}$ formed in the catalytic oxidation of cyclohexane contains ${ }^{18} \mathrm{O}$.

With cyclohexyl hydroperoxide as the main reaction product one may expect the formation of isomeric cyclohexane

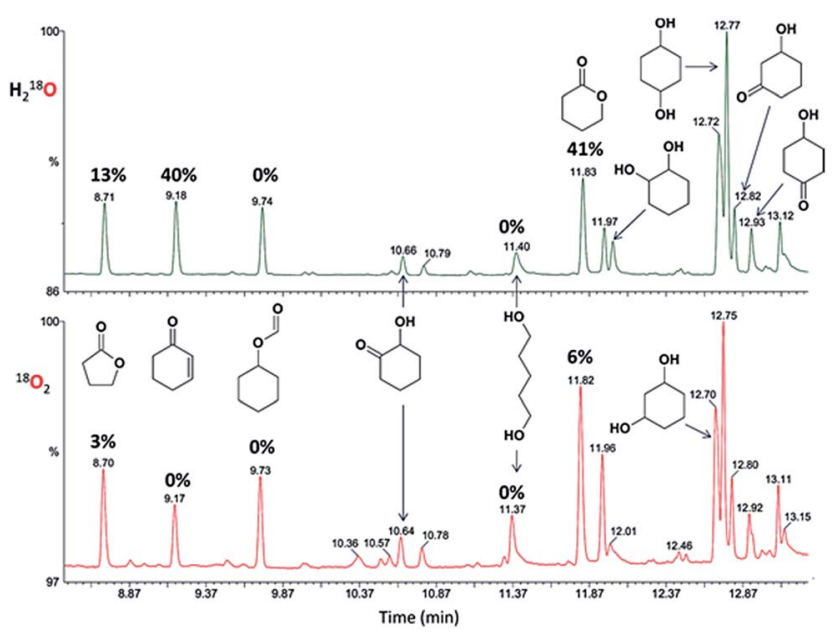

Fig. 18 Oxidation of cyclohexane by the " $\mathrm{I}-\mathrm{HNO}_{3}-\mathrm{H}_{2} \mathrm{O}_{2}$ " system in the presence of $\mathrm{H}_{2}{ }^{18} \mathrm{O}$ (top) or ${ }^{18} \mathrm{O}_{2}$ atmosphere (bottom). Chromatograms of the reaction samples taken after $180 \mathrm{~min}$ time and reduced with $\mathrm{PPh}_{3}$ show over-oxidation products. The peaks of main products (cyclohexanol and cyclohexanone) appear at 8.1 and $8.3 \mathrm{~min}$, respectively, and they are omitted for clarity. Numbers (\%) above peaks indicate the content of ${ }^{18} \mathrm{O}$ in the corresponding products. Incorporation of ${ }^{18} \mathrm{O}$ into the cyclohexanediols and hydroxycyclohexanones is given in Table 2. 
Table 2 Content of ${ }^{18} \mathrm{O}(\%)$ in cyclohexanediols and hydroxycyclohexanones (main by-products) produced in the oxidation of cyclohexane by the "I- $\mathrm{HNO}_{3}-\mathrm{H}_{2} \mathrm{O}_{2}$ " system in the presence of $\mathrm{H}_{2}{ }^{18} \mathrm{O}$ or in $\mathrm{a}^{18} \mathrm{O}_{2}$ atmosphere

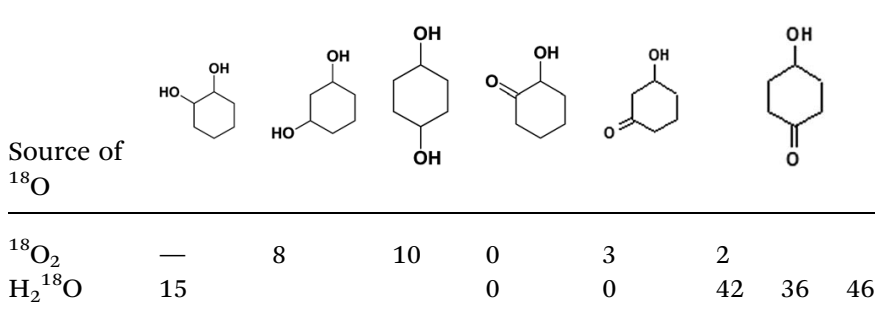

dihydroperoxides, $c-\mathrm{C}_{6} \mathrm{H}_{10}(\mathrm{OOH})_{2}$ as the main over-oxidation products which would produce 1,2-, 1,3-, and 1,4-cyclohexanediols upon reduction with $\mathrm{PPh}_{3}$. The over-oxidation patterns for both ${ }^{18} \mathrm{O}_{2}$ and $\mathrm{H}_{2}{ }^{18} \mathrm{O}$ catalytic tests are similar, showing by-products typical for hydroxyl radical oxidation of cyclohexane (Fig. 18).

For the case of ${ }^{18} \mathrm{O}_{2}$ test, the incorporation of labeled oxygen into the 1,3- and 1,4-cyclohexanediols was found to be $c a$. at $9 \%$ level (Fig. 18, Table 2). This is close to a level of ${ }^{18} \mathrm{O}$ incorporation into the main product, cyclohexanol. Doubly labeled diols were not detected. The amount of 1,2-cyclohexanediol was insufficient for reliable estimate of its ${ }^{18} \mathrm{O}$ incorporation levels. An interesting observation is that the content of labeled oxygen in hydroxycyclohexanones was found to be at nearly zero level (0, 3 and $2 \%$ of ${ }^{18} \mathrm{O}$ for 2 -, 3- and 4-hydroxycyclohexanones, respectively).

One can select two general pathways (Fig. 19a and b) towards cyclohexanediols and another two (c and d) towards hydroxycyclohexanones. Since the incorporation of ${ }^{18} \mathrm{O}$ into the diols almost equals to that for cyclohexanol one may assume that most of diols are formed through the route $a$, whereas route $b$ is

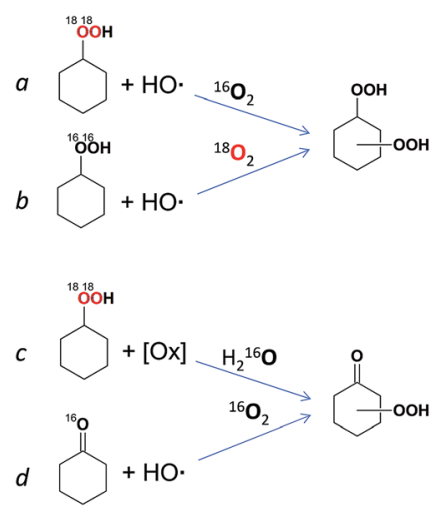

Fig. 19 Main processes which could lead to different isotopic isomers of cyclohexanediols and hydroxycyclohexanones (shown in the form of corresponding hydroperoxides; pathways a-d) in the oxidation of cyclohexane under ${ }^{18} \mathrm{O}_{2}$. Here [Ox] means oxidation to form a ketone, either in a way which does not involve $\mathrm{O}_{2}$ participation, or via hydroxyl radical attack with the subsequent decomposition of hydroperoxide to form ketone. Route a results in a labeled cyclohexanediol, while both routes $\mathrm{a}$ and $\mathrm{d}$ do not form labeled hydroxycyclohexanone (see the text). unfavourable due to depletion of the ${ }^{18} \mathrm{O}_{2}$ amount at reaction time $>2 \mathrm{~h}$. Hence, it can be concluded that the route $\mathrm{d}$ will always give unlabeled hydroxycyclohexanones (no free ${ }^{18} \mathrm{O}_{2}$ available). Pathway $\mathrm{c}$ will give unlabeled product due to the oxygen exchange with excess of unlabeled water $\mathrm{H}_{2}{ }^{16} \mathrm{O}$, and this will not depend on the isotopic composition of the introduced ketone group. Considering the contributions of both routes $\mathrm{c}$ and $\mathrm{d}$ to be nearly equal, at least twice less content of ${ }^{18} \mathrm{O}$ in hydroxycyclohexanones in comparison with cyclohexanediols may be expected. This assumption is in agreement with the observed level of ${ }^{18} \mathrm{O}$ incorporation into the hydroxycyclohexanones (Table 2). Besides, the 2-hydroxycyclohexanone was found to be $100 \%{ }^{18} \mathrm{O}$-free. The effect of lowered ${ }^{18} \mathrm{O}$ incorporation into this by-product was already observed by some of $\mathrm{us}^{21}$ in the copper catalysed cyclohexane oxidation under the atmosphere of ${ }^{18} \mathrm{O}_{2}$.

The content of ${ }^{18} \mathrm{O}$ in the by-products of reaction in the presence of $\mathrm{H}_{2}{ }^{18} \mathrm{O}$ reveals expected levels if one considers that (i) alcohols (oxidation products) are ${ }^{18} \mathrm{O}$-free and (ii) ketones get ${ }^{18} \mathrm{O}$ from the oxygen exchange with $\mathrm{H}_{2}{ }^{18} \mathrm{O}$. Hydroxycyclohexanones were found to contain notable levels of ${ }^{18} \mathrm{O}$. Comparison of mass-spectra of hydroxycyclohexanones (ESI, Fig. S6-S8†) taken within the current work with the previously obtained spectra (where labeling of hydroxyl groups was assumed) shows some differences leading to the conclusion that in the present case the labeled oxygen is located at the ketone group, in agreement with the postulated mechanisms.

Surprisingly, the reaction in the presence of $\mathrm{H}_{2}{ }^{18} \mathrm{O}$ gave some portion of labeled 1,2-cyclohexahediol whereas incorporation of ${ }^{18} \mathrm{O}$ was observed neither in cyclohexanol nor in $1,3-$ or $1,4-$ cyclohexanediols. The accumulation of labeled 1,2-diol is shown in Fig. 20. As can be seen incorporation of ${ }^{18} \mathrm{O}$ into the 1,2-diol reaches $15 \%$ at $3 \mathrm{~h}$ reaction time. Blank test has been performed $\left([\right.$ cis-1,2-diol $]=0.02 \mathrm{M},\left[\mathrm{HNO}_{3}\right]=0.05 \mathrm{M},\left[\mathrm{H}_{2}{ }^{18} \mathrm{O}\right]=$ $2.6 \mathrm{M}$ in $\mathrm{CH}_{3} \mathrm{CN}$, at room temperature) and showed no labeled diol formation. However, we still cannot exclude the presence of

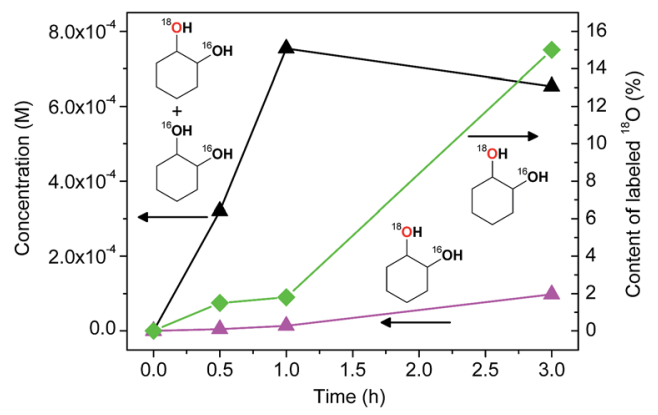

Fig. 20 Kinetic curves of accumulation with time of 1,2-cyclohexananediol containing both partially labeled (the sum ${ }^{16} \mathrm{O}+{ }^{18} \mathrm{O}$ ) and completely ${ }^{18} \mathrm{O}$-labeled oxygenates (left $Y$-axis). Incorporation of the labeled oxygen into the 1,2-cyclohexanediol in the course of the cyclohexane oxidations is also shown (right $Y$-axis). Conditions: []$_{0}=2$ $\times 10^{-4} \mathrm{M} ;\left[\mathrm{HNO}_{3}\right]_{0}=0.05 \mathrm{M} ;\left[\mathrm{H}_{2} \mathrm{O}_{2}\right]_{0}=0.91 \mathrm{M} ;$ [cyclohexane $]_{0}=0.48$ $\mathrm{M} ; 30{ }^{\circ} \mathrm{C} ;\left[\mathrm{H}_{2}{ }^{18} \mathrm{O}\right]_{0}=2.15 \mathrm{M}$. The yields and isotopic abundances were measured after reduction of the reaction samples with $\mathrm{PPh}_{3}$. 

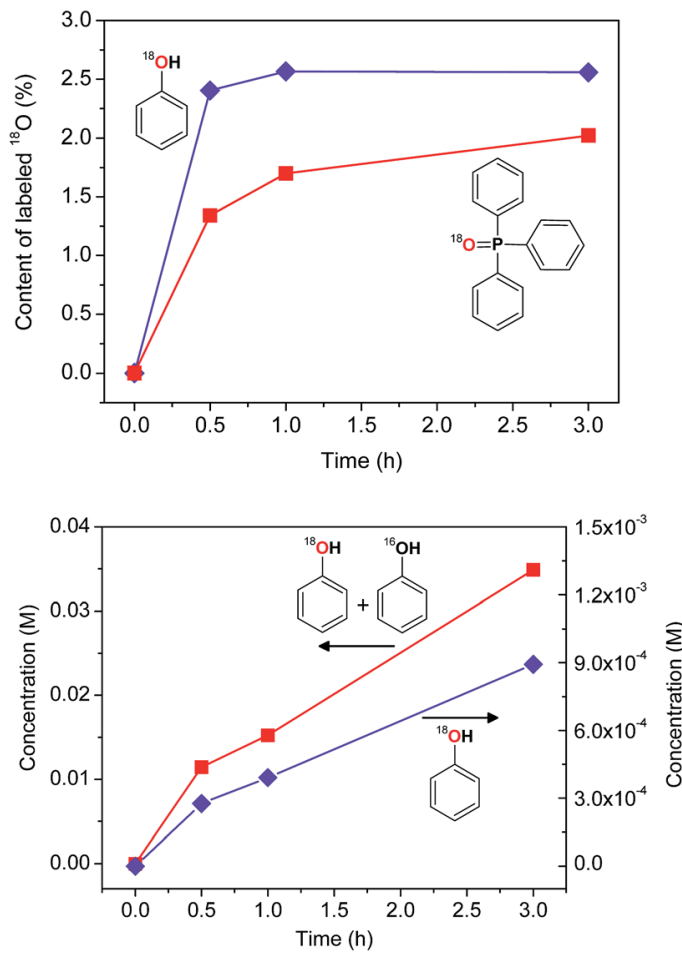

Fig. 21 Incorporation of the labeled oxygen into phenol and triphenylphosphine oxide (top) in the course of the benzene oxidations. Conditions: $[\mathrm{I}]_{0}=2 \times 10^{-4} \mathrm{M} ;\left[\mathrm{HNO}_{3}\right]_{0}=0.05 \mathrm{M} ;\left[\mathrm{H}_{2} \mathrm{O}_{2}\right]_{0}=0.7 \mathrm{M}$; [benzene $]_{0}=0.5 \mathrm{M} ; 20{ }^{\circ} \mathrm{C} ;\left[\mathrm{H}_{2}{ }^{18} \mathrm{O}\right]_{0}=2.15 \mathrm{M}$. Bottom graph: Kinetic curves of accumulation with time of phenol containing both partially labeled (the sum ${ }^{16} \mathrm{O}+{ }^{18} \mathrm{O}$ ) and completely ${ }^{18} \mathrm{O}$-labeled oxygenates. The yields and isotopic abundances were measured after reduction of the reaction samples with $\mathrm{PPh}_{3}$.

some non-catalytic mechanisms leading to labeled 1,2-cyclohexanol under the conditions of the experiment.
The accumulation of labeled phenol in the oxidation of benzene in the presence of $\mathrm{H}_{2}{ }^{18} \mathrm{O}$ was studied using the same reaction conditions as for cyclohexane oxidation, except of lower amount of the oxidant $\left[\mathrm{H}_{2} \mathrm{O}_{2}\right]_{0}=0.7 \mathrm{M}$ (Fig. 21). The attack of benzene by hydroxyl radical proceeds in a different manner compared to the case of saturated hydrocarbons, the phenol oxygen appears from $\mathrm{HO}^{\circ}$ but not from dioxygen or water. ${ }^{41 c}$ However, oxidation of benzene using catalyst I resulted in $c a .2 .5 \%$ incorporation of ${ }^{18} \mathrm{O}$ into the phenol (the overall yield based on the benzene is $7 \%$ after $3 \mathrm{~h}$ reaction time). Close amounts of ${ }^{18} \mathrm{O}$ were found in $\mathrm{O}=\mathrm{PPh}_{3}$ indicating the presence of some mechanisms involving exchange with water oxygen.

\section{Catalytic oxidative amidation of alcohols}

Oxidation of alcohols into amides has attracted considerable attention since the pioneering results on ruthenium ${ }^{42}$ and rhodium $^{43}$ catalysis. These borrowing hydrogen approaches allowed to circumvent the drawbacks associated with classical amide bond synthesis involving carboxylic acids, amines and coupling agents. Toxicity of the reagents as well as solvent used for this kind of coupling prompted chemists to search for alternative routes. Since ruthenium and rhodium are highly expensive metals, cheap transition metals such as $\mathrm{Mn}, \mathrm{Zn}, \mathrm{Cu}$ and $\mathrm{Fe}$ were investigated to perform amide formation in the presence of TBHP (tert-butylhydroperoxide). ${ }^{44}$ We already reported ${ }^{20 c}$ that copper silsesquioxanes gave outstanding results in this kind of reaction, allowing to go down to $100 \mathrm{ppm}$ in copper, and reach TON and TOF values up to 9400 and $392 \mathrm{~h}^{-1}$, respectively. As a continuing study and since iron salts have been proven by us ${ }^{4 a a, b}$ and others ${ }^{44, d}$ to perform efficiently this tandem oxidation/amidation reaction, compound I was evaluated in this reaction.

To compare with our previous reports using $\mathrm{FeCl}_{2} \cdot 4 \mathrm{H}_{2} \mathrm{O},{ }^{4 a a, b}$ the following study was performed taking into account the quantity of iron involved, keeping in mind that complex I

Table 3 Optimization of the reaction conditions ${ }^{a}$

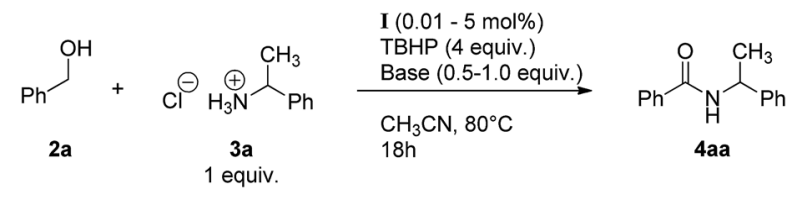

\begin{tabular}{lllll}
\hline Entry & Mol\% of Fe & Equiv. 2a & Base (equiv.) & Yield (\%) \\
\hline $1^{c}$ & 5 & 1.5 & $\mathrm{CaCO}_{3}(1)$ & 73 \\
2 & 0.05 & 1.5 & $\mathrm{CaCO}_{3}(1)$ & 68 \\
3 & 0.05 & 1.5 & $\mathrm{CaCO}_{3}{ }^{d}(1)$ & 65 \\
4 & 0.05 & 2 & $\mathrm{CaCO}_{3}(1)$ & 77 \\
5 & 0.01 & 2 & $\mathrm{CaCO}_{3}(1)$ & 50 \\
6 & 0.05 & 2 & $\mathrm{CaCO}_{3}(0.5)$ & 81 \\
7 & 0.05 & 2 & $\mathrm{None}^{b}$ & 22 \\
$8^{e}$ & $10\left(\mathrm{FeCl}_{2} \cdot 4 \mathrm{H}_{2} \mathrm{O}\right)$ & 1.3 & $\mathrm{CaCO}_{3}{ }^{d}$ & 86
\end{tabular}

${ }^{a}$ Reaction conditions: $(\alpha)$-methylbenzylamine $\cdot \mathrm{HCl}(0.5 \mathrm{mmol})$, benzyl alcohol $\left(0.75^{-1} \mathrm{mmol}\right), \mathrm{CaCO}_{3} 99 \%$ pure $(0.5 \mathrm{mmol})$, TBHP $\left(70 \%\right.$ in $\mathrm{H}_{2} \mathrm{O}, 4$ equiv., $2.0 \mathrm{mmol}), \mathrm{CH}_{3} \mathrm{CN}(1 \mathrm{~mL}), 80{ }^{\circ} \mathrm{C}, 18 \mathrm{~h} .{ }^{b} \mathrm{TON}=(\mathrm{mmol}$ of product $) /($ mmol of $\mathrm{Fe}) ; \mathrm{TOF}=(\mathrm{mmol}$ of product $) /($ mmol of $\mathrm{Fe}) /($ reaction time $)$.

${ }^{c}$ Reaction performed in 4 h. ${ }^{d} \mathrm{CaCO}_{3} 99.995 \%$ pure was used. ${ }^{e}$ Result from ref. $44 b$. 
Table 4 Variation of the amine at low catalyst loading ${ }^{a}$

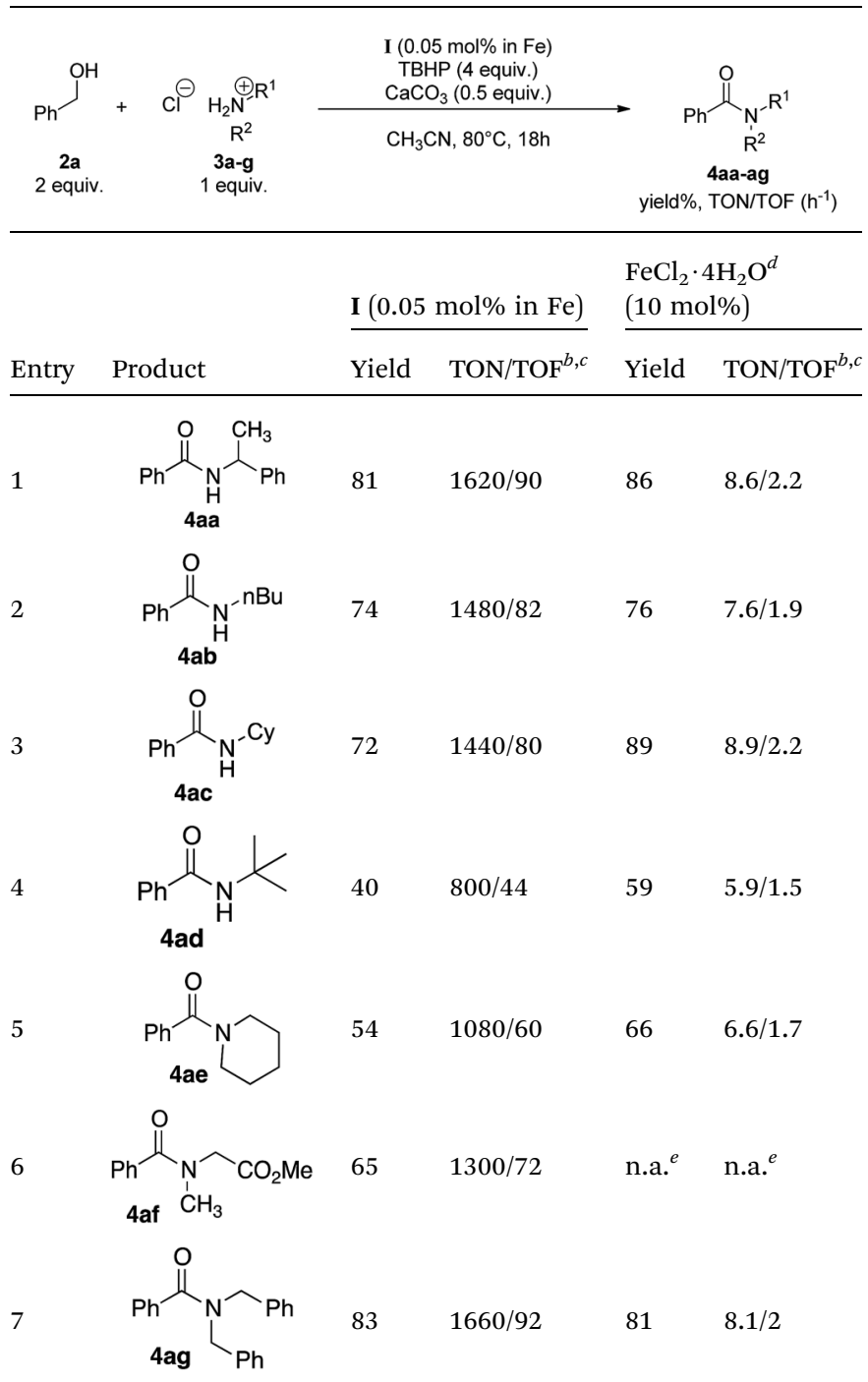

${ }^{a}$ Reaction conditions: amine $\cdot \mathrm{HCl}(0.5 \mathrm{mmol})$, benzyl alcohol (1.0 mmol), $\mathrm{CaCO}_{3} 99 \%$ pure $(0.25 \mathrm{mmol})$, TBHP (70\% in $\mathrm{H}_{2} \mathrm{O}, 4$ equiv., 2 $\mathrm{mmol}), \mathbf{I}(0.05 \mathrm{~mol} \%$ in $\mathrm{Fe}), \mathrm{CH}_{3} \mathrm{CN}(1 \mathrm{~mL}), 80{ }^{\circ} \mathrm{C}, 18 \mathrm{~h}$. Isolated yields are given. ${ }^{b} \mathrm{TON}=(\mathrm{mmol}$ of product $) /(\mathrm{mmol}$ of $\mathrm{Fe}) .{ }^{c} \mathrm{TOF}=$ TON/(reaction time); given in $\mathrm{h}^{-1} .{ }^{d}$ Obtained from lit. ${ }^{44 b}{ }^{e}$ n.a. $=$ not available.

contains 6 iron atoms. In the presence of $5 \mathrm{~mol} \%$ of iron, TBHP ( 4 equiv.) and calcium carbonate, $(\alpha)$-methylbenzylamine $\cdot \mathrm{HCl}$ 3a was converted into corresponding benzamide 4 aa in $73 \%$ yield after $4 \mathrm{~h}$ (Table 3, entry 1). Decreasing catalyst loading was found possible with a concomitant increase of the reaction time to 18 hours. Thus, a loading of $0.05 \mathrm{~mol} \%$ in iron was enough to obtain $68 \%$ of $4 a a$ (Table 3, entry 2). At this loading, the purity of the base is of importance since metallic contaminants could catalyze the amidation reaction. Contrary to what was observed with copper cages, ${ }^{20 c}$ the purity of $\mathrm{CaCO}_{3}, 99.995 \%$ or $>99 \%$ pure, had little influence on the outcome of the reaction (Table 3 , entries 2 and 3). Eventually, an increase in the stoichiometry of benzyl alcohol 2 a allowed to reach $77 \%$ yield (Table 3 , entry 4). Decreasing even more the catalyst loading to $100 \mathrm{ppm}$ in iron

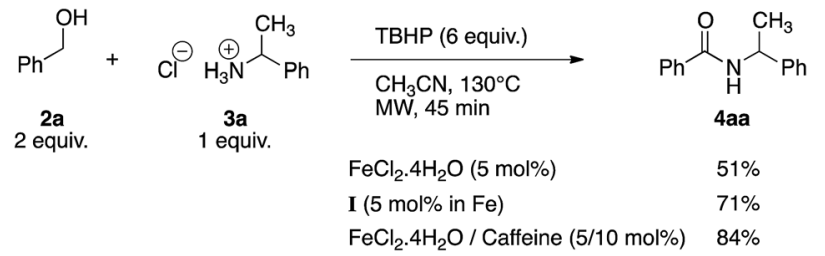

Scheme 3 Comparison of $\mathrm{I}$ and $\mathrm{FeCl}_{2} \cdot 4 \mathrm{H}_{2} \mathrm{O}$ under microwave activation.

was detrimental to the reaction (Table 3, entry 5). Finally, reducing the amount of base to 0.5 equivalent allowed to slightly increase the isolated yield to $81 \%$ (Table 3 , entry 6). A control experiment demonstrated that $\mathrm{CaCO}_{3}$ was required to obtain good yield in this reaction (Table 3, entry 7). As a comparison, the optimized catalytic conditions obtained in the presence of precatalyst $\mathbf{I}$ allowed to reach TON and TOF values of 1620 and $90 \mathrm{~h}^{-1}$, respectively, while $\mathrm{FeCl}_{2} \cdot 4 \mathrm{H}_{2} \mathrm{O}$ permitted TON and TOF values of solely 8.6 and $2.2 \mathrm{~h}^{-1}$, respectively (Table 3, entries 6 and 8).

In order to prove the usefulness of these new conditions, several amines were reacted with benzyl alcohol $\mathbf{2 a}$ in the presence of only 500 ppm of iron (Table 4). Delightfully, even though isolated yields were not always better than with $10 \mathrm{~mol} \%$ of $\mathrm{FeCl}_{2} \cdot 4 \mathrm{H}_{2} \mathrm{O}$, TON and TOF values were found much higher, thus proving the robustness of iron cage compound I. Primary amines 3a-c reacted correctly giving corresponding amides 4aa-ac in $72-81 \%$ yield (Table 4 , entries $1-3$ ). However, highly hindered tert-butyl amine was moderately converted into 4ad (Table 4, entry 4). Nevertheless, TON and TOF values were 135and 30-fold higher than with $\mathrm{FeCl}_{2} \cdot 4 \mathrm{H}_{2} \mathrm{O}$, respectively. Secondary amines $\mathbf{3 e}-\mathbf{g}$ were also benzoylated efficiently, with yields up to $83 \%$ and TON and TOF values up to 1660 and 92 $\mathrm{h}^{-1}$, respectively (Table 4 , entries $5-7$ ).

In parallel to this study in batch conditions, I was evaluated under microwave-activated conditions, which were reported to give, at that time, the highest TON and TOF values for the oxidative amidation using TBHP as oxidant (Scheme 3). ${ }^{4 a}$ Interestingly, under the exact same conditions, precatalyst I outperformed $\mathrm{FeCl}_{2} \cdot 4 \mathrm{H}_{2} \mathrm{O}$ (51\% yield), giving amide 4 aa in $71 \%$ yield. Such result proves the robustness of $\mathbf{I}$, resulting from a stabilizing effect of the silsesquioxane ligands around the iron centers. Nevertheless, the reported catalytic system $\mathrm{FeCl}_{2} \cdot 4 \mathrm{H}_{2}$ $\mathrm{O} /$ caffeine was still found superior to I, yielding 4 aa in $84 \%$.

\section{Conclusions}

Simple one-pot procedure of alkaline condensation of triethoxyphenylsilane followed by interaction with $\mathrm{FeCl}_{3}$ allowed us to obtain cage-like sodium, iron(III) phenylsilsesquioxane $\left[\left(\mathrm{PhSiO}_{1.5}\right)_{20}\left(\mathrm{FeO}_{1.5}\right)_{6}\left(\mathrm{NaO}_{0.5}\right)_{8}(n-\mathrm{BuOH})_{9.6}\left(\mathrm{C}_{7} \mathrm{H}_{8}\right)\right]$ I in a high yield. Specificity of the product I composition (two triiron(III) clusters, "embraced" by cyclic and acyclic silsesquioxane ligands) provokes the formation of a remarkable Asian Lanternlike molecular architecture. 
The structure of compound I was studied by single crystal Xray, EXAFS, topological analysis and DFT calculations. Significant distortion of iron-containing topologically identical 2M3-1 clusters due to the interaction with polydentate ligand is found. This fact causes the appearance of a spin-frustrated system and spin glass behaviour. Taking into account that the chains are straight, it is not surprising that these are packed parallel with bups-to-hollow mutual disposition of metallasilsesquioxane cluster in the hexagonal lattice fashion.

Compound I can be considered as an inorganic model of alkane oxygenases. Alkanes and benzene can be oxidized in acetonitrile solution to the corresponding alkyl hydroperoxides and phenol, respectively, by hydrogen peroxide in air in the presence of catalytic amounts of complex I and nitric acid. The regioselectivity parameters and a kinetic study of the oxidation led to the conclusion that alkanes are transformed into the corresponding oxygenates with the participation of hydroxyl radicals. To understand the peculiarities of the catalytic mechanisms the reactions have been performed under the atmosphere of labeled dioxygen $\left({ }^{18} \mathrm{O}_{2}\right)$ or in the presence of ${ }^{18} \mathrm{O}$-labelled water $\left(\mathrm{H}_{2}{ }^{18} \mathrm{O}\right)$. From previous studies, ${ }^{21,41 c}$ for the catalytic system oxidizing with hydroxyl radicals, $c a$. $50 \%$ incorporation of ${ }^{18} \mathrm{O}$ from the ${ }^{18} \mathrm{O}_{2}$ into the cyclohexyl hydroperoxide was expected. However, in the case of I-catalyzed oxidation of cyclohexane under ${ }^{18} \mathrm{O}_{2}$ only $12 \%$ of labeled cyclohexanol was observed. The effect of lowered ${ }^{18} \mathrm{O}$ level may be due to the lower activity of the present catalytic system. This level fully corresponds to the observed amount of labelled $\mathrm{O}=\mathrm{PPh}_{3}$ of $c a .15 \%$.

The experiments on cyclohexane oxidation performed in the presence of ${ }^{18} \mathrm{O}$-labeled water revealed no ${ }^{18} \mathrm{O}$ incorporation into the main product, cyclohexyl hydroperoxide, and corresponding cyclohexanol. These results point to the absence of high-valent metal oxo species, many of which are known to possess fast oxygen exchange with water. The investigation of by-products patterns for both ${ }^{18} \mathrm{O}_{2}$ and $\mathrm{H}_{2}{ }^{18} \mathrm{O}$ experiments showed few anomalies, namely the presence of ${ }^{18} \mathrm{O}$-free 1,5 pentanediol in both cases (alcohols are expected to contain ${ }^{18} \mathrm{O}$ from ${ }^{18} \mathrm{O}_{2}$ ) and $15 \%$ of ${ }^{18} \mathrm{O}$ incorporation into 1,2 -cyclohexanediol in case of experiment in the presence of $\mathrm{H}_{2}{ }^{18} \mathrm{O}$. Moreover, in the last case 1,3- and 1,4-cyclohexanediols were found to be ${ }^{18} \mathrm{O}$-free and blank experiment revealed no oxygen exchange between 1,2-cyclohexanediol and water. We assume that these observations may indicate the presence of minor reaction mechanisms, which proceed without the participation of free radicals. Such conclusion is also supported by the detection of small amounts of labeled phenol in the oxidation of benzene catalyzed by $\mathbf{I}$.

Complex I was also evaluated in the oxidative amidation of benzylic alcohols. The peculiar properties of I allowed to work at $500 \mathrm{ppm}$ in iron. Hence, secondary and tertiary amides were obtained with TON and TOF values as high as 1660 and $92 \mathrm{~h}^{-1}$, respectively. The effectiveness of I was also highlighted under microwave-activated conditions, giving better results than $\mathrm{FeCl}_{2} \cdot 4 \mathrm{H}_{2} \mathrm{O}$ alone. Those encouraging results demonstrated that development of new iron silsesquioxane structures could lead to even more active precatalysts.

\section{Experimental section}

$\mathrm{PhSi}(\mathrm{OEt})_{3}$ was purchased from Sigma Aldrich and was used as received. IR spectra were recorded on FTIR Shimadzu IR Prestige-21. IR spectrum in Nujol for solids and liquid solution in thin film were obtained using $\mathrm{KBr}$ discs.

\section{Synthesis of compound I}

$\mathrm{PhSi}(\mathrm{OEt})_{3}(4 \mathrm{~g}, 0.017 \mathrm{~mol})$ and sodium hydroxide $(0.865 \mathrm{~g}$, $0.021 \mathrm{~mol}$ ) were dissolved in $80 \mathrm{~mL}$ of EtOH. After complete dissolution of sodium hydroxide, the mixture was heated at reflux for $2.5 \mathrm{~h}$ and then anhydrous iron(III) chloride $(0.809 \mathrm{~g}$, $0.005 \mathrm{~mol}$ ) was added. The resulting brick-colored solution was additionally heated at reflux for $3 \mathrm{~h}$ and then cooled down to room temperature. Finally, a mixture of $20 \mathrm{~mL}$ of $n$-butanol/10 $\mathrm{mL}$ of toluene was added to the solution, then the reaction mixture was filtered off. Formation of a crystalline product with single crystals useful for X-ray diffraction analysis was observed in solution after approximately two weeks. After ceasing of the crystal fraction growth, the solution was decanted and the solid fraction was dried in vacuum. $1.65 \mathrm{~g}$ (60\% yield in calculation for $\left.\left[\left(\mathrm{PhSiO}_{1.5}\right)_{20}\left(\mathrm{FeO}_{1.5}\right)_{6}\left(\mathrm{NaO}_{0.5}\right)_{8}\right]\right)$ of brick-colored product was obtained.

IR (Nujol): (PhSi): 1126 (s), 1104 (sh) $\mathrm{cm}^{-1}$; (Ph overtones) 1959, 1898, 1822, $1774 \mathrm{~cm}^{-1}$; $\nu_{\mathrm{SiO}(\mathrm{Si})}$ : 1068, 1038, $1024 \mathrm{~cm}^{-1}$; $\nu_{\mathrm{SiO}(\mathrm{Fe})}: 997(\mathrm{~s}), 978(\mathrm{~s}), 921$ (sh) $\mathrm{cm}^{-1} ; \nu_{\mathrm{FeO}(\mathrm{Fe})}: 521,514,506$ $\mathrm{cm}^{-1} ; \delta_{\mathrm{SiO}(\mathrm{Si})}: 467,445 \mathrm{~cm}^{-1} ; \delta_{\mathrm{SiO}(\mathrm{Fe})}: 409,396 \mathrm{~cm}^{-1}$. Elemental analysis: calcd $\left[\left(\mathrm{PhSiO}_{1.5}\right)_{20}\left(\mathrm{FeO}_{1.5}\right)_{6}\left(\mathrm{NaO}_{0.5}\right)_{8}\right]: \mathrm{Fe}, 10.12 ; \mathrm{Na}$, 5.56; Si, 16.97. Found: Fe, 9.97; Na, 5.49; Si, 16.78.

\section{X-ray structure determination}

Single crystals of $\mathrm{C}_{165.8} \mathrm{H}_{204.8} \mathrm{Fe}_{6} \mathrm{Na}_{8} \mathrm{O}_{52.6} \mathrm{Si}_{20}$ were red prisms. A suitable crystal was selected and intensities of reflections were measured on a Bruker Smart 1000 CCD area detector diffractometer. The crystal was kept at $100.15 \mathrm{~K}$ during data collection. Using Olex2 (ref. 45) the structure was solved with the XS structure solution program ${ }^{46}$ using Direct Methods and refined with the ShelXL refinement package ${ }^{47}$ using least squares minimisation.

Crystal data for $\mathrm{C}_{165.8} \mathrm{H}_{204.8} \mathrm{Fe}_{6} \mathrm{Na}_{8} \mathrm{O}_{52.6} \mathrm{Si}_{20}(M=4120.10 \mathrm{~g}$ $\mathrm{mol}^{-1}$ ): monoclinic, space group $P 2_{1} / c$ (no. 14), $a=30.0277(16)$ $\AA, b=20.3021(11) \AA, c=32.2979(17) \AA, \beta=92.9200(10)^{\circ}, V=$ $19664.1(18) \AA^{3}, Z=4, T=100.15 \mathrm{~K}, \mu(\mathrm{MoK} \alpha)=0.647 \mathrm{~mm}^{-1}$, $D_{\text {calc }}=1.392 \mathrm{~g} \mathrm{~cm}^{-3}, 147601$ reflections measured $\left(2.806^{\circ} \leq 2 \Theta\right.$ $\left.\leq 47.914^{\circ}\right), 30628$ unique $\left(R_{\text {int }}=0.1094, R_{\text {sigma }}=0.0805\right)$ which were used in all calculations. The final $R_{1}$ was $0.0688(I>2 \sigma(I))$ and $\mathrm{w} R_{2}$ was 0.2094 (all data).

\section{XAS experiments}

The Fe K-edge X-ray spectra for sample in the solid state were collected at the beamline "Structural Materials Science"48a using the equipment of "Kurchatov Synchrotron Radiation Source" (Moscow, Russia). The storage ring with an electron beam energy of $2.5 \mathrm{GeV}$ and a current of $80-100 \mathrm{~mA}$ was used as the source of radiation. All the spectra were collected in the 
transmission mode using a $\mathrm{Si}$ (111) channel-cut monochromator. The powder samples were spread over an adhesive Kapton tape that was folded into several layers to achieve an appropriate combination of total absorption and absorption edge jump. EXAFS data $\left(\chi_{\exp }(k)\right)$ were analyzed using the IFEFFIT data analysis package. ${ }^{48 b}$ EXAFS data reduction used standard procedures for the pre-edge subtraction and spline background removal. The radial pair distribution functions around the Fe ions were obtained by the Fourier transformation (FT) of the $k^{2}$-weighted EXAFS functions $\chi_{\exp }(k)$ over the ranges of photoelectron wave numbers $k=2.5-15.0 \AA^{-1}$. The structural parameters, including interatomic distances $\left(R_{i}\right)$, coordination numbers $\left(N_{i}\right)$ and Debye-Waller factors $\left(\sigma^{2}\right)$, were found by the non-linear fit of theoretical spectra (formula (A)) to experimental ones.

$$
\chi(k)=S_{0}{ }^{2} \sum_{i=1}^{n} \frac{N_{i} F_{i}(k)}{R_{i}{ }^{2} k} \mathrm{e}^{-\frac{2 R_{i}}{\lambda(k)}} \mathrm{e}^{-2 \sigma_{i}{ }^{2} k^{2}} \sin \left(2 k R_{i}+\psi_{i}(k)\right)
$$

The theoretical data were simulated using the photoelectron mean free path $\lambda(k)$, amplitude $F_{i}(k)$ and phase shift $\Psi_{i}(k)$ calculated $a b$ initio using program FEFF6. ${ }^{48 c}$ For the refined interatomic distances $\left(R_{i}\right)$ the statistical error is $0.01-0.02 \AA$ for the first coordination sphere.

\section{Computational details}

Full geometry optimizations were carried out with the Gaussian09 (Revision C.01) package. Calculation provided by two-layer ONIOM technique. The high core layer containing Fe$\mathrm{O}-\mathrm{Si}-\mathrm{O}-\mathrm{Na}$ skeleton was calculated by DFT/PBE0 functional with $6-31 \mathrm{G}(\mathrm{d}, \mathrm{p})$ basis set. The medium layer consists from $\mathrm{C}_{6} \mathrm{H}_{5}$ groups attached to silicon atom. Frequency calculations were performed for optimized complex in the gas phase and are reported without the use of scaling factors. The nature of all the stationary points on the potential energy surfaces was confirmed by a vibrational analysis.

\section{Magnetic measurements}

Magnetic susceptibility data were collected with a Quantum Design MPMS-XL SQUID magnetometer working in the temperature range $1.8-350 \mathrm{~K}$ with an applied magnetic field up to 7 tesla. The data were corrected for the sample holder (polyethylene film) and the diamagnetic contributions calculated from the Pascal's constants. ${ }^{49}$

\section{Catalytic oxidation of hydrocarbons}

The reactions of alkanes were typically carried out in air in thermostated Pyrex cylindrical vessels with vigorous stirring and using MeCN as solvent. Typically, catalyst I and the cocatalyst (acid) were introduced into the reaction mixture in the form of stock solutions in acetonitrile. The substrate (hydrocarbon) was then added and the reaction started when hydrogen peroxide was introduced in one portion. (CAUTION: The combination of air or molecular oxygen and $\mathrm{H}_{2} \mathrm{O}_{2}$ with organic compounds at elevated temperatures may be explosive!). The reactions after addition of nitromethane as a standard compound were analyzed by GC (instrument 'HP 5890 - Serie-II'; fused silica capillary columns column HewlettPackard; the stationary phase was polyethyleneglycol: INNOWAX with parameters $25 \mathrm{~m} \times 0.2 \mathrm{~mm} \times 0.4 \mu \mathrm{m}$; carrier gas was helium). Attribution of peaks was made by comparison with chromatograms of authentic samples. Blank experiments with cyclohexane showed that in the absence of catalyst I no products were formed.

\section{Experiments with labeled ${ }^{18} \mathrm{O}_{2}$ and $\mathrm{H}_{2}{ }^{18} \mathrm{O}$}

A Perkin-Elmer Clarus 600 gas chromatograph, equipped with two capillary columns (SGE BPX5; $30 \mathrm{~m} \times 0.32 \mathrm{~mm} \times 25 \mu \mathrm{m}$ ), one having EI-MS (electron impact) and the other one with FID detector, was used for analyses of the reaction mixtures. The following GC conditions have been used: $50{ }^{\circ} \mathrm{C}$ ( $\left.3 \mathrm{~min}\right), 50-120$ ${ }^{\circ} \mathrm{C}$ (8 degrees per minute), $120-300{ }^{\circ} \mathrm{C}\left(35^{\circ} \mathrm{C}\right.$ per minute), $300{ }^{\circ} \mathrm{C}$ (4.11 min), $21 \mathrm{~min}$ total run time; $200{ }^{\circ} \mathrm{C}$ injector temperature. Helium was used as the carrier gas ( $1 \mathrm{~mL}$ per minute flow). All EI mass spectra were recorded with $70 \mathrm{eV}$ energy. Labeled dioxygen $\left(99 \%\right.$ of $\left.{ }^{18} \mathrm{O}\right)$ was purchased from CortecNet. Labeled water ( $97 \%$ of $\left.{ }^{18} \mathrm{O}\right)$ was purchased from Cambridge Isotope Laboratories, Inc. For experiments with ${ }^{18} \mathrm{O}_{2}$, freshly prepared catalytic reaction mixtures were frozen with liquid nitrogen, pumped and filled with $\mathrm{N}_{2}$ a few times in order to remove air. The procedure was repeated a few times, unfreezing the solutions under $\mathrm{N}_{2}$ atmosphere. Then the mixtures were pumped again, vacuum pump turned off, Schlenk flasks with vacuum inside were filled with ${ }^{18} \mathrm{O}_{2}$ using a syringe through a septa and heated up to $30^{\circ} \mathrm{C}$ with a possibility of gas flow to compensate excessive pressure. For experiments with $\mathrm{H}_{2}{ }^{18} \mathrm{O}$, a reduced reaction volume was used $(2.5 \mathrm{~mL})$ and $0.1 \mathrm{~mL}$ of labeled water was added prior to addition of the oxidant (hydrogen peroxide). The ${ }^{16} \mathrm{O}$ and ${ }^{18} \mathrm{O}$ compositions of the oxygenated products were determined by the relative abundances of mass peaks at $\mathrm{m} / \mathrm{z}=$ $57 / 59$ for cyclohexanol and $m / z=\mathbf{M}^{+} / \mathbf{M}^{+}+2$ molecular ion peaks for other compounds.

\section{Catalytic oxidative amidation of alcohols}

Procedure at low catalyst loading. In a sealed tube were added successively amine hydrochloride $(0.5 \mathrm{mmol}), \mathrm{CaCO}_{3}$ (25.0 mg, $0.25 \mathrm{mmol}), \mathrm{CH}_{3} \mathrm{CN}(1 \mathrm{~mL}), 1(50 \mu \mathrm{L}$ of a solution of $2.8 \mathrm{mg}$ of $\mathbf{I}$ in $1 \mathrm{~mL}$ of EtOAc), benzylic alcohol $(104 \mu \mathrm{L}, 1.0$ $\mathrm{mmol})$, and TBHP (70\% in $\left.\mathrm{H}_{2} \mathrm{O}, 140 \mu \mathrm{L}, 1.0 \mathrm{mmol}\right)$. The mixture was stirred at $80{ }^{\circ} \mathrm{C}$ for $2 \mathrm{~h}$ and TBHP $\left(70 \%\right.$ in $\mathrm{H}_{2} \mathrm{O}, 140 \mu \mathrm{L}, 1.0$ $\mathrm{mmol}$ ) were again added to the mixture. After $16 \mathrm{~h}$ at $80^{\circ} \mathrm{C}$, the mixture was cooled to room temperature and $1 \mathrm{~N} \mathrm{HCl}$ and AcOEt were added. The mixture was extracted twice with AcOEt, and the combined organic phase was washed with saturated solution of $\mathrm{NaHCO}_{3}$, brine, and concentrated under reduced pressure. To remove the excess of benzylic alcohol, $80 \mathrm{~mL}$ of $\mathrm{H}_{2} \mathrm{O}$ were added and evaporated under reduced pressure. Crude product was then purified using silica gel chromatography using gradients of cyclohexane/AcOEt to yield the pure compounds. 
Procedure under microwave activation. In a $0.5-2.0 \mathrm{~mL}$ microwave reactor were added I $(13.9 \mathrm{mg}, 0.025 \mathrm{mmol}, 5 \mathrm{~mol} \%$ in $\mathrm{Fe}$ ), and ( $\alpha$ )-methylbenzylamine $\cdot \mathrm{HCl}(78.8 \mathrm{mg}, 0.5 \mathrm{mmol}, 1$ equiv.). $1 \mathrm{~mL}$ of $\mathrm{CH}_{3} \mathrm{CN}$, benzyl alcohol (104 $\mu \mathrm{L}, 1.0 \mathrm{mmol}, 2$ equiv.) and tert-butylhydroperoxide (70\% in $\mathrm{H}_{2} \mathrm{O}, 140 \mu \mathrm{L}, 2$ equiv.) were then added. After $15 \mathrm{~min}$ of stirring at $130{ }^{\circ} \mathrm{C}$ under microwave irradiation, another 2 equiv. of tert-butylhydroperoxide $\left(70 \%\right.$ in $\left.\mathrm{H}_{2} \mathrm{O}, 140 \mu \mathrm{L}\right)$ were added, and the mixture was further stirred for $15 \mathrm{~min}$ at $130{ }^{\circ} \mathrm{C}$. Once again, 2 other equiv. of tert-butylhydroperoxide $\left(70 \%\right.$ in $\left.\mathrm{H}_{2} \mathrm{O}, 140 \mu \mathrm{L}\right)$ were added and the mixture was stirred for $15 \mathrm{~min}$ at $130{ }^{\circ} \mathrm{C}$. After cooling to rt, $\mathrm{HCl} 1 \mathrm{~N}(5 \mathrm{~mL})$ and AcOEt $(5 \mathrm{~mL})$ were added. The mixture was extracted with AcOEt $(2 \times 5 \mathrm{~mL})$, and the combined organic phases were washed with saturated aqueous $\mathrm{NaHCO}_{3}$ solution $(10 \mathrm{~mL})$, brine $(10 \mathrm{~mL})$, dried over magnesium sulfate and concentrated under reduced pressure. $\mathrm{H}_{2} \mathrm{O}(50 \mathrm{~mL})$ was then added to evaporate remaining benzyl alcohol. The crude mixture was purified by chromatography on silica gel using mixtures of cyclohexane and ethyl acetate as eluent.

\section{Acknowledgements}

This work has been supported by the Russian Foundation for Basic Research (Grants 14-03-00713; 16-03-00206, 16-03-00254), the French Embassy in Moscow (Programme André Mazon), the Balard Foundation, the University of Montpellier, the Plateforme d'Analyse et de Caractérisation (PAC Balard), the Centre National de la Recherche Scientifique (CNRS), through the Groupe de Recherche International (GDRI) Homogenous catalysis for sustainable development (CH2D), the Fundação para a Ciência e Tecnologia (FCT), Portugal (projects PTDC/ QUIQUI/102150/2008, PTDC/QUI-QUI/121526/2010, Project PTDC/QEQ-QIN/3967/2014 and UID/QUI/0100/2013, fellowship SFRH/BPD/99533/2014), and the "Science without Borders Program, Brazil-Russia”, CAPES (grant A017-2013). L. S. S. and G. B. S. express their gratitude to the FCT and Group 1 of Centro de Química Estrutural for making it possible for them to stay at the Instituto Superior Técnico, University of Lisbon, as invited scientists and to perform a part of the present work (all the funding for the invited scientist fellowship comes entirely from this Group).

\section{References}

1 (a) A. Choudhury, S. Natarajan and C. N. R. Rao, Chem. Mater., 1999, 11, 2316-2318; (b) D. R. Turner, S. N. Pek, J. D. Cashion, B. Moubaraki, K. S. Murray and S. R. Batten, Dalton Trans., 2008, 6877-6879; (c) A. K. Dutta and R. Ghosh, Inorg. Chem. Commun., 2011, 14, 337-342; (d) Y.-F. Zeng, X. Hu, L. Xue, S.-J. Liu, T.-L. Hu and X.-H. Bu, Inorg. Chem., 2012, 51, 9571-9573; (e) T.-Z. Zhang, Z.-M. Zhang, Y. Lu and E.-B. Wang, J. Coord. Chem., 2012, 65, 48-54 and references cited therein.

2 (a) E. K. Brechin, Chem. Commun., 2005, 5141-5153; (b) N. T. Madhu, J.-K. Tang, I. J. Hewitt, R. Clérac, W. Wernsdorfer, J. v. Slageren, C. E. Anson and A. K. Powell, Polyhedron, 2005, 24, 2864-2869; (c)
A. J. Tasiopoulos and S. P. Perlepes, Dalton Trans., 2008, 5537-5555; (d) L. Gregoli, C. Danieli, A. L. Barra, P. Neugebauer, G. Pellegrino, G. Poneti, R. Sessoli and A. Cornia, Chem.-Eur. J., 2009, 15, 6456-6467 and references cited therein; (e) M. J. Rodriguez-Douton, A. Cornia, R. Sessoli, L. Sorace and A.-L. Barra, Dalton Trans., 2010, 39, 5851-5859; ( $f$ ) C. Schlegel, E. Burzurí, F. Luis, F. Moro, M. Manoli, E. K. Brechin, M. Murrie and J. van Slageren, Chem.-Eur. J., 2010, 16, 10178-10185; $(g)$ Y.-Y. Zhu, X. Guo, C. Cui, B.-W. Wang, Z.-M. Wang and S. Gao, Chem. Commun., 2011, 47, 8049-8051; $(h)$ Y. Hou, X. Fang, K. D. Kwon, L. J. Criscenti, D. Davis, T. Lambert and M. Nyman, Eur. J. Inorg. Chem., 2013, 1780-1787 and references cited therein; (i) Y.-Y. Zhu, C. Cui, K. Qian, J. Yin, B.-W. Wang, Z.-M. Wang and S. Gao, Dalton Trans., 2014, 43, 11897-11907.

3 X.-Y. Cao, J. W. Hubbard, J. Guerrero-Medina, A. J. Hernandez-Maldonado, L. Mathivathanan, C. Rinaldi, Y. Sanakis and R. G. Raptis, Dalton Trans., 2015, 44, 33993409.

4 (a) M. Murugesu, R. Clérac, W. Wernsdorfer, C. E. Anson and A. K. Powell, Angew. Chem., Int. Ed., 2005, 44, 6678-6682; (b) R. W. Saalfrank, I. Bernt, E. Uller and F. Hampel, Angew. Chem., 1997, 109, 2596-2599; (c) D. Foguet-Albiol, K. A. Abboud and G. Christou, Chem. Commun., 2005, 4282-4284; (d) G. Jiang, J. Bai, H. Xing, Y. Li and X. You, Cryst. Growth Des., 2006, 6, 1264-1266.

5 (a) X.-F. Ma, J.-L. Tian, W. Gu, S. Gao, S.-P. Yan and D.-Z. Liao, Inorg. Chem. Commun., 2008, 11, 256-259; (b) Z.-M. Zhang, S. Yao, Y.-G. Li, R. Clérac, Y. Lu, Z.-M. Su and E.-B. Wang, J. Am. Chem. Soc., 2009, 131, 14600-14601; (c) R. Singh, A. Banerjee, E. Colacio and K. K. Rajak, Inorg. Chem., 2009, 48, 4753-4762.

6 Y.-L. Miao, J.-L. Liu, Z.-J. Lin, Y.-C. Ou, J.-D. Leng and M.-L. Tong, Dalton Trans., 2010, 39, 4893-4902.

7 (a) C. Papatriantafyllopoulou, C. M. Kizas, M. J. Manos, A. Boudalis, Y. Sanakis and A. J. Tasiopoulos, Polyhedron, 2013, 64, 218-230; (b) A. Ferguson, L. H. Thomas and M. Murrie, Polyhedron, 2013, 52, 227-233.

8 (a) M. Mohan and B. Paramhans, Croat. Chem. Acta, 1981, 54, 173-182; (b) W.-Q. Chen, Y.-M. Chen, T. Lei, W. Liu and Y. Li, Inorg. Chem. Commun., 2012, 19, 4-9.

9 Y. Z. Zheng, M. L. Tong, W. Xue, W. X. Zhang, X. M. Chen, F. Grandjean and G. J. Long, Angew. Chem., Int. Ed., 2007, 46, 6076-6080.

10 (a) R. Murugavel, A. Voigt, M. G. Walawalkar and H. W. Roesky, Chem. Rev., 1996, 96, 2205-2236; (b) L. King and A. C. Sullivan, Coord. Chem. Rev., 1999, 189, 19-57; (c) H. W. Roesky, G. Anantharaman, V. Chandrasekhar, V. Jancik and S. Singh, Chem.-Eur. J., 2004, 10, 4106-4114; (d) F. T. Edelmann, Metallasilsesquioxanes. Synthetic and Structural Studies, Wiley, 2007; (e) A. J. Ward, A. F. Masters and T. Maschmeyer, in Applications of Polyhedral Oligomeric Silsesquioxanes, Springer, 2011, pp. 135-166; $(f)$ E. V. Beletskiy, Z. Shen, M. V. Riofski, X. Hou, J. R. Gallagher, J. T. Miller, Y. Wu, H. H. Kung and M. C. Kung, Chem. Commun., 2014, 50, 15699-15701; $(g)$ 
F. Schax, E. Bill, C. Herwig and C. Limberg, Angew. Chem., Int. Ed., 2014, 53, 12741-12745; $(h)$ A. N. Bilyachenko, A. I. Yalymov, A. A. Korlyukov, J. Long, J. Larionova, Y. Guari, Y. V. Zubavichus, A. L. Trigub, E. S. Shubina, I. L. Eremenko, N. N. Efimov and M. M. Levitsky, Chem.Eur. J., 2015, 21, 18563-18565; (i) A. N. Bilyachenko, A. I. Yalymov, A. A. Korlyukov, J. Long, J. Larionova, Y. Guari, A. V. Vologzhanina, M. Eskova, E. S. Shubina and M. M. Levitsky, Dalton Trans., 2016, DOI: 10.1039/ C6DT00113K, accepted manuscript.

11 (a) L. Deng, A. Majumdar, W. Lo and R. H. Holm, Inorg. Chem., 2010, 49, 11118-11126; (b) D. Pinkert and C. Limberg, Chem.-Eur. J., 2014, 20, 9166-9175.

12 (a) A. E. Shilov and G. B. Shul'pin, Chem. Rev., 1997, 97, 2879-2932; (b) A. E. Shilov and G. B. Shul'pin, Activation and catalytic reactions of saturated hydrocarbons in the presence of metal complexes, Springer Science \& Business Media, 2001, vol. 21; (c) E. G. Chepaikin, Russ. Chem. Rev., 2011, 80, 363-396; (d) A. M. Kirillov, M. V. Kirillova and A. J. Pombeiro, Adv. Inorg. Chem., 2013, 65, 1-31; (e) A. Sivaramakrishna, P. Suman, E. Veerashekhar Goud, S. Janardan, C. Sravani, T. Sandeep, K. Vijayakrishna and H. S. Clayton, J. Coord. Chem., 2013, 66, 2091-2109; (f) A. B. Sorokin, Chem. Rev., 2013, 113, 8152-8191; $(g)$ L. M. D. R. S. Martins and A. J. L. Pombeiro, Coord. Chem. Rev., 2014, 265, 74-88; (h) I. Gryca, B. Machura, J. G. Malecki, L. S. Shul'pina, A. J. L. Pombeiro and G. B. Shul'pin, Dalton Trans., 2014, 43, 5759-5776.

13 A. Mayer and C. Bolm, in Iron Catalysis in Organic Chemistry, ed. B. Plietker, Wiley-VCH, 2008, pp. 73-92.

14 (a) R. N. Austin and J. T. Groves, Metallomics, 2011, 3, 775787; (b) E. Torras and M. Ayala, in Comprehensive Inorganic Chemistry, ed. J. Reedijk, K. Poeppelmeier and L. Casella, Elsevier, 2013, vol. 6, pp. 685-735; (c) M. R. A. Blomberg, T. Borowski, F. Himo, R.-Z. Liao and P. E. M. Siegbahn, Chem. Rev., 2014, 114, 3601-3658; (d) T. L. Poulos, Chem. Rev., 2014, 114, 3919-3962.

15 M.-H. Baik, B. F. Gherman, R. A. Friesner and S. J. Lippard, J. Am. Chem. Soc., 2002, 124, 14608-14615.

16 (a) G. B. Shul'pin, Org. Biomol. Chem., 2010, 8, 4217-4228; (b) G. B. Shul'pin, in Comprehensive Inorganic Chemistry II, ed J. Reedijk, K. Poeppelmeier and L. Casella, Elsevier, 2nd edn, 2013, vol. 6, pp. 79-104; (c) G. B. Shul'pin, Dalton Trans., 2013, 42, 12794-12818.

17 J. Green and H. Dalton, J. Biol. Chem., 1989, 264, 1769817703.

18 Reviews: (a) B. Meunier, Biomimetic oxidations catalyzed by transition metal complexes, World Scientific, 2000; (b) T. Punniyamurthy, S. Velusamy and J. Iqbal, Chem. Rev., 2005, 105, 2329-2364; (c) S. Tanase and E. Bouwman, Adv. Inorg. Chem., 2006, 58, 29; (d) A. M. Kirillov and G. B. Shul'pin, Coord. Chem. Rev., 2013, 257, 732-754.

19 Selected recent papers: (a) D. Lee and S. J. Lippard, Inorg. Chem., 2002, 41, 2704-2719; (b) G. V. Nizova, B. Krebs, G. Süss-Fink, S. Schindler, L. Westerheide, L. Gonzalez Cuervo and G. B. Shul'pin, Tetrahedron, 2002, 58, 92319237; (c) S. Yoon and S. J. Lippard, J. Am. Chem. Soc., 2004,
126, 16692-16693; (d) R. F. Moreira, E. Y. Tshuva and S. J. Lippard, Inorg. Chem., 2004, 43, 4427-4434; (e) M. N. Mortensen, B. Jensen, A. Hazell, A. D. Bond and C. J. McKenzie, Dalton Trans., 2004, 3396-3402; (f) G. B. Shul'pin, G. V. Nizova, Y. N. Kozlov, L. Gonzalez Cuervo and G. Süss-Fink, Adv. Synth. Catal., 2004, 346, 317-332; $(g)$ S. Yoon and S. J. Lippard, J. Am. Chem. Soc., 2005, 127, 8386-8397; (h) E. C. Carson and S. J. Lippard, Inorg. Chem., 2006, 45, 828-836; (i) E. C. Carson and S. J. Lippard, Inorg. Chem., 2006, 45, 837-848; (j) S. Yoon and S. J. Lippard, Inorg. Chem., 2006, 45, 5438-5446; $(k)$ V. B. Romakh, B. Therrien, G. Süss-Fink and G. B. Shul'pin, Inorg. Chem., 2007, 46, 3166-3175; (l) M. Jarenmark, E. A. Turitsyna, M. Haukka, A. A. Shteinman and E. Nordlander, New J. Chem., 2010, 34, 2118-2121; $(m)$ B. M. Pires, D. M. Silva, L. C. Visentin, V. Drago, N. M. F. Carvalho, R. B. Faria and O. A. C. Antunes, Inorg. Chim. Acta, 2013, 407, 69-81; (n) M. N. M. Milunovic, L. M. D. R. S. Martins, E. C. B. A. Alegria, A. J. L. Pombeiro, R. Krachler, G. Trettenhahn, C. Turta, S. Shova and V. B. Arion, Dalton Trans., 2013, 42, 14388-14401; (o) B. Das, A. Al-Hunaiti, M. Haukka, S. Demeshko, S. Meyer, A. A. Shteinman, F. Meyer, T. Repo and E. Nordlander, Eur. J. Inorg. Chem., 2015, 3590-3601.

20 (a) A. N. Bilyachenko, M. S. Dronova, A. I. Yalymov, A. A. Korlyukov, L. S. Shul'pina, D. E. Arkhipov, E. S. Shubina, M. M. Levitsky, A. D. Kirilin and G. B. Shul'pin, Eur. J. Inorg. Chem., 2013, 5240-5246; (b) M. S. Dronova, A. N. Bilyachenko, A. I. Yalymov, Y. N. Kozlov, L. S. Shul'pina, A. A. Korlyukov, D. E. Arkhipov, M. M. Levitsky, E. S. Shubina and G. B. Shul'pin, Dalton Trans., 2014, 43, 872-882; (c) A. N. Bilyachenko, M. S. Dronova, A. I. Yalymov, F. Lamaty, X. Bantreil, J. Martinez, C. Bizet, L. S. Shul'pina, A. A. Korlyukov, D. E. Arkhipov, M. M. Levitsky, E. S. Shubina, A. M. Kirillov and G. B. Shul'pin, Chem.-Eur. J., 2015, 21, 8758-8770.

21 M. M. Vinogradov, Y. N. Kozlov, A. N. Bilyachenko, D. S. Nesterov, L. S. Shul'pina, Y. V. Zubavichus, A. J. L. Pombeiro, M. M. Levitsky, A. I. Yalymov and G. B. Shul'pin, New J. Chem., 2015, 39, 187-199.

22 A. Zhdanov, N. Sergienko and E. Trankina, Russian Chemical Journal, 2001, 44-48.

23 (a) G. J. Long, W. T. Robinson, W. P. Tappmeyer and D. L. Bridges, J. Chem. Soc., Dalton Trans., 1973, 573-579; (b) R. D. Cannon, U. A. Jayasooriya, R. Wu, S. K. arapKoske, J. A. Stride, O. F. Nielsen, R. P. White, G. J. Kearley and D. Summerfield, J. Am. Chem. Soc., 1994, 116, 11869-11874; (c) F. E. Sowrey, C. Tilford, S. Wocadlo, C. E. Anson, A. K. Powell, S. M. Bennington, W. Montfrooij, U. A. Jayasooriya and R. D. Cannon, J. Chem. Soc., Dalton Trans., 2001, 862-866; (d) W. Hibbs, P. J. van Koningsbruggen, A. M. Arif, W. W. Shum and J. S. Miller, Inorg. Chem., 2003, 42, 5645-5653; (e) V. Mereacre, M. Nakano, J. Gómez-Segura, I. Imaz, 
C. Sporer, K. Wurst, J. Veciana, C. Turta, D. Ruiz-Molina and P. Jaitner, Inorg. Chem., 2006, 45, 10443-10445.

24 P. Alborés and E. Rentschler, Inorg. Chem., 2008, 47, 79607962.

25 D. L. Long, P. Kögerler, L. J. Farrugia and L. Cronin, Chem.Asian J., 2006, 1, 352-357.

26 (a) T. M. Anderson, X. Zhang, K. I. Hardcastle and C. L. Hill, Inorg. Chem., 2002, 41, 2477-2488; (b) J. Wang, J.-W. Zhao, H.-Y. Zhao, B.-F. Yang, H. He and G.-Y. Yang, CrystEngComm, 2014, 16, 252-259; (c) J. Zhao, Q. Han, D. Shi, L. Chen, P. Ma, J. Wang and J. Niu, J. Solid State Chem., 2011, 184, 2756-2761; (d) A. Caneschi, A. Cornia, A. C. Fabretti, D. Gatteschi and W. Malavasi, Inorg. Chem., 1995, 34, 4660-4668; (e) B. Li, J.-W. Zhao, S.-T. Zheng and G.-Y. Yang, Inorg. Chem. Commun., 2009, 12, 69-71.

27 M. M. Levitsky and A. N. Bilyachenko, Coord. Chem. Rev., 2016, 306, 235-269.

28 M. Wilke, F. Farges, P.-E. Petit, G. E. Brown and F. Martin, Am. Mineral., 2001, 86, 714-730.

29 L. Néel, Ann. Geophys., 1949, 99-136.

30 J. A. Mydosh, Spin glasses, Taylor and Francis, Washington DC, 1993.

31 (a) L. Lundgren, P. Svendlich, P. Nordblad and O. Beckman, Phys. Rev. Lett., 1983, 51, 911-914; (b) E. Vincent, J. Hammann, M. Ocio, J.-P. Bouchaud and L. F. Cugliandolo, in Complex Behaviour of Glassy Systems, Springer, 1997, pp. 184-219.

32 L. Lartigue, S. Oh, E. Prouzet, Y. Guari and J. Larionova, Mater. Chem. Phys., 2012, 132, 438-445.

33 (a) J. M. D. Coey, Phys. Rev. Lett., 1971, 27, 1140-1142; (b) S. D. Tiwari and K. P. Rajeev, Phys. Rev. B, 2005, 72, 104433.

34 (a) J. A. Mydosh, J. Magn. Magn. Mater., 1996, 157-158, 606610; (b) P. Schiffer, A. P. Ramirez, D. A. Huse, P. L. Gammel, U. Yaron, D. J. Bishop and A. J. Valentino, Phys. Rev. Lett., 1995, 74, 2379-2382.

35 M. Frisch, G. Trucks, H. B. Schlegel, G. Scuseria, M. Robb, J. Cheeseman, G. Scalmani, V. Barone, B. Mennucci, G. Petersson and H. E. A. Nakatsuji, Wallingford, CT, 2009, 19, 227-238.

36 S. Dapprich, I. Komáromi, K. S. Byun, K. Morokuma and M. J. Frisch, J. Mol. Struct.: THEOCHEM, 1999, 461-462, 1-21. 37 Y. Zhao and D. G. Truhlar, Theor. Chem. Acc., 2008, 120, 215241.

38 M. Swart, M. Güell, J. M. Luis and M. Solà, J. Phys. Chem. A, 2010, 114, 7191-7197.

39 J. J. Stewart, J. Mol. Model., 2007, 13, 1173-1213.

40 (a) G. B. Shul'pin, J. Mol. Catal. A: Chem., 2002, 189, 39-66; (b)

G. B. Shul'pin, C. R. Chim., 2003, 6, 163-178; (c)

G. B. Shul'pin, Mini-Rev. Org. Chem., 2009, 6, 95-104; (d)
G. B. Shul'pin, Y. N. Kozlov, L. S. Shul'pina, A. R. Kudinov and D. Mandelli, Inorg. Chem., 2009, 48, 10480-10482; (e) G. B. Shul'pin, Y. N. Kozlov, L. S. Shul'pina and P. V. Petrovskiy, Appl. Organomet. Chem., 2010, 24, 464-472. 41 (a) E. P. Talsi and K. P. Bryliakov, Coord. Chem. Rev., 2012, 256, 1418-1434; (b) L. S. Shul'pina, A. R. Kudinov, D. Mandelli, W. A. Carvalho, Y. N. Kozlov, M. M. Vinogradov, N. S. Ikonnikov and G. B. Shul'pin, J. Organomet. Chem., 2015, 793, 217-231; (c) M. M. Vinogradov, Y. N. Kozlov, D. S. Nesterov, L. S. Shul'pina, A. J. L. Pombeiro and G. B. Shul'pin, Catal. Sci. Technol., 2014, 4, 3214-3226; (d) R. V. Ottenbacher, D. G. Samsonenko, E. P. Talsi and K. P. Bryliakov, ACS Catal., 2014, 4, 1599-1606; (e) E. P. Talsi, R. V. Ottenbacher and K. P. Bryliakov, J. Organomet. Chem., 2015, 793, 102-107. 42 (a) L. U. Nordstrøm, H. Vogt and R. Madsen, J. Am. Chem. Soc., 2008, 130, 17672-17673; (b) C. Gunanathan, Y. BenDavid and D. Milstein, Science, 2007, 317, 790-792; (c) T. Naota and S.-I. Murahashi, Synlett, 1991, 693-694.

43 (a) T. Zweifel, J. V. Naubron and H. Grützmacher, Angew. Chem., Int. Ed., 2009, 48, 559-563; (b) K.-i. Fujita, Y. Takahashi, M. Owaki, K. Yamamoto and R. Yamaguchi, Org. Lett., 2004, 6, 2785-2788.

44 (a) X. Bantreil, P. Navals, J. Martinez and F. Lamaty, Eur. J. Org. Chem., 2015, 417-422; (b) X. Bantreil, N. Kanfar, N. Gehin, E. Golliard, P. Ohlmann, J. Martinez and F. Lamaty, Tetrahedron, 2014, 70, 5093-5099; (c) S. Gaspa, A. Porcheddu and L. De Luca, Org. Biomol. Chem., 2013, 11, 3803-3807; (d) S. C. Ghosh, J. S. Y. Ngiam, A. M. Seayad, D. T. Tuan, C. W. Johannes and A. Chen, Tetrahedron Lett., 2013, 54, 4922-4925; (e) X.-F. Wu, M. Sharif, A. PewsDavtyan, P. Langer, K. Ayub and M. Beller, Eur. J. Org. Chem., 2013, 2783-2787; (f) X. Bantreil, C. Fleith, J. Martinez and F. Lamaty, ChemCatChem, 2012, 4, 19221925.

45 O. V. Dolomanov, L. J. Bourhis, R. J. Gildea, J. A. K. Howard and H. Puschmann, J. Appl. Crystallogr., 2009, 42, 339-341. 46 G. Sheldrick, Acta Crystallogr., Sect. A: Cryst. Phys., Diffr., Theor. Gen. Crystallogr., 2008, 64, 112-122.

47 G. Sheldrick, Acta Crystallogr., Sect. C: Struct. Chem., 2015, 71, 3-8.

48 (a) A. A. Chernyshov, A. A. Veligzhanin and Y. V. Zubavichus, Nucl. Instrum. Methods Phys. Res., 2009, 603, 95-98; (b) M. Newville, J. Synchrotron Radiat., 2001, 8, 96-100; (c) S. I. Zabinski, J. J. Rehr, A. Ankudinov and R. C. Alber, Phys. Rev. B, 1995, 52, 2995.

49 A. T. Casey and S. Mitra, Theory and Applications of Molecular Paramagnetism, ed. E. A. Boudreaux and L. N. Mulay, John Wiley \& Sons, New York, 1976. 